\title{
A new hybrid approach based on discrete differential evolution algorithm to enhancement solutions of quadratic assignment problem
}

\author{
Asaad Shakir Hameed ${ }^{a *}$, Burhanuddin Mohd Aboobaider ${ }^{a}$, Modhi Lafta Mutar and Ngo Hea \\ Choon $^{\text {a }}$
}

${ }^{a}$ Faculty of Information and Communication Technology, Universiti Teknikal Malaysia Melaka, Hang Tuah Jaya, 76100, Durian Tunggal, Melaka, Malaysia

\begin{tabular}{l}
\hline C H R O N I C L E \\
\hline Article history: \\
Received April 12019 \\
Received in Revised Format \\
June 192019 \\
Accepted June 192019 \\
Available online \\
June 192019 \\
\hline Keywords: \\
Combinatorial optimization \\
Problems \\
Facility Layout Problem \\
Quadratic Assignment Problem \\
Discrete Differential Evolution \\
Algorithm \\
Tabu Search Algorithm
\end{tabular}

\section{Introduction} \begin{abstract}
A B S T R A C T
The Combinatorial Optimization Problem (COPs) is one of the branches of applied mathematics and computer sciences, which is accompanied by many problems such as Facility Layout Problem (FLP), Vehicle Routing Problem (VRP), etc. Even though the use of several mathematical formulations is employed for FLP, Quadratic Assignment Problem (QAP) is one of the most commonly used. One of the major problems of Combinatorial NP-hard Optimization Problem is QAP mathematical model. Consequently, many approaches have been introduced to solve this problem, and these approaches are classified as Approximate and Exact methods. With QAP, each facility is allocated to just one location, thereby reducing cost in terms of aggregate distances weighted by flow values. The primary aim of this study is to propose a hybrid approach which combines Discrete Differential Evolution (DDE) algorithm and Tabu Search (TS) algorithm to enhance solutions of QAP model, to reduce the distances between the locations by finding the best distribution of $\mathrm{N}$ facilities to $\mathrm{N}$ locations, and to implement hybrid approach based on discrete differential evolution (HDDETS) on many instances of QAP from the benchmark. The performance of the proposed approach has been tested on several sets of instances from the data set of QAP and the results obtained have shown the effective performance of the proposed algorithm in improving several solutions of QAP in reasonable time. Afterwards, the proposed approach is compared with other recent methods in the literature review. Based on the computation results, the proposed hybrid approach outperforms the other methods.
\end{abstract}

The emergence of Combinatorial Optimization Problems (COPs) from theory and practice poses a great challenge that has continued to attract the attention of practitioners, researchers and academicians globally for the last five decades. Facility Layout Problem is an example of such combinatorial problems and finding a solution to this problem has remained a major challenge (Scalia et al., 2019). The main purpose of finding a solution to this problem is to enable the arrangement of departments within the boundaries of the predefined facility such that the functions can efficiently interact with one another, while the total cost of mobility is reduced. Many studies have been carried out in the area of facility 
layout problems, but most of them have only focused on studying facility layout problems in manufacturing facilities, with just a few of them analyzing this problem within hospital domain. The modelling of FLP was first carried out as a quadratic assignment problem (QAP) by (Koopmans \& Beckmann, 1957). According to Samanta et al. (2018), these COPs emerge from real-life situations. The use of discrete formulations is employed in layout problems which involve determining possible positions of facilities prior to their optimization. QAP is commonly used for this kind of problem. The QAP is regarded as a problem of NP-Hard combinatorial optimization (Şahinkoç \& Bilge, 2018), which serves as a model for many real-life applications such as hospital layout, backboard wiring, campus layout, scheduling and designing of keyboard typewriter, etc. ever since the QAP was formulated, the attention of researchers has been drawn to it because of its importance in theory and practice, and most importantly because of how complex it is (Duman et al., 2012; Benlic \& Hao, 2013; Kaviani et al., 2014; Abdel-Basset et al., 2018a, Cela et al., 2018). The FLP has been introduced as a QAP in order to identify the ideal allocation of $N$ facilities to $N$ locations, where there must be equality between the number of locations and number of facilities. Researchers around the world have accepted the complexity associated with finding a solution, but now, there is no available polynomial time algorithm that can be used to solve QAP. In recent times, the approximate algorithms have been used more than the exact algorithms, because it can find the optimal solution with unreasonable time. However, most of the times it is impossible to solve a problem that is more than 20 within a reasonable period of time (Abdel-Baset et al., 2017). Therefore, researchers are more interested in employing the use of meta-heuristic and heuristic approaches to solve huge QAP problems. The motivation of this paper is proposing a novel approximate meta-heuristic algorithm that can enable the most efficient allocation of $N$ facilities to $N$ locations $(N>$ 30) of QAP. It is hoped that this approach will, in turn, enhance the reduction of cost while the problem is solved within the shortest time possible. The use of different methods, which are classified as a heuristic, meta-heuristic and exact methods has been employed in solving this challenging problem. Out of the three categories of methods, researchers are paying more attention to meta-heuristic methods, and this is evident in its increased usage in solving problems associated with optimization. Regardless of the inability of these methods to solve problems optimally, their efficiency is guaranteed especially when the models are complex. One of the meta-heuristic methods that are widely used in models of healthcare facility location is Tabu search (TS) (Zhang et al., 2010). Apart from Tabu, there are other methods that are used in solving such problems, such as Genetic Algorithm (GA) (Radiah Shariff \& Noor Hasnah Moin, 2012). Pareto Ant Colony Optimization (P-ACO) (Doerner et al., 2007), and Simulate Annealing (SA) (Syam \& Côté, 2010). One of the greatest problems associated with the exact methods is their cost of computation with more time, and for this reason, this study is carried out to find the best solutions for QAP. In order to achieve this, a new method is proposed in this study. This study seeks to achieve more objectives as follows: (i) The major objective of this study is to propose a hybrid approach which combines Discrete Differential Evolution (DDE) algorithm and Tabu Search (TS) algorithm for enhancing solutions of QAP model, (ii) To minimizethe cost through reducing the distances between the locations by finding the best distribution of $N$ facilities from $N$ locations, and (iii) To implement HDDETS on many instances of QAP from the benchmark.

The other sections of this paper are as follows. Section 2 introduces the Quadratic Assignment Problem QAP. In Section 3 the Review of Literature is provided. In Section 4, the algorithm that has been proposed (HDDETS) has been examined and discussed. The Computational Results are discussed in Section 5. Lastly, the conclusions and some recommendations for future studies are given in Section 6.

\section{Quadratic Assignment Problem QAP}

The QAP has several real-life applications, which makes it an interesting area of study for researchers since its inception (Czapiński, 2013; Abdelkafi et al., 2015; Çela et al., 2017). The QAP mathematical model has been presented as follows:

$$
\min f(\pi)=\sum_{i=1}^{n} \sum_{j=1}^{n} F_{i j} D_{\pi(i) \pi(j)}
$$


Overall permutations $_{\pi \in P_{n}}$.

The model of QAP consists of two matrices each of them size $N \times N, N=1,2, \ldots, \mathrm{n}$.

- The $F$ refers to the flow or weight between each pair of facilities is represented by $F_{i j}$ denoting the flow from facility $i$ to facility $j$;

- The $D$ connotes the distance that exist between each pair of locations being represented by $D_{i j}$, which denotes the distance from location $i$ to location $j$;

- $\pi$ is the best way through which a solution to a QAP problem can be represented.

- The aim is to allocate $N$ facilities to $N$ locations at a low cost.

\section{Literature Review}

QAP remains a major problem that is yet to have an exact solution. To this end, many researchers have invested so many resources into finding the most appropriate solution to this problem, and they have as well used several methods with different techniques to solve the problem. In this section, the review of literature is presented to show some of the several techniques that other researchers have used to solve the QAP. The Discrete Particle Swarm Optimization (DPSO) algorithm was introduced by Pradeepmon et al. Sridharan (2016). In a study carried out by Pradeepmon (2018), the DPSO algorithm was modified and named Modified DPSO. This development was also aimed at solving the QAP. Also, in (Shukla, 2015) the Bat Algorithm (BA) was used for the same purpose. Similarly, the study conducted by Riffi et al. (2017) aimed at enhancing the BA search strategy by introducing a new method. In their proposed method, the Discrete Bat Algorithm (DBA) was combined with BA, an enhanced uniform crossover, and a 2-exchange neighborhood method. The Ant Colony Optimization (ACO) algorithm has been suggested by Xia and Zhou (2018). In the research conducted by Abdel-Basset et al. (2018b), a new approach known as the WAITS was introduced. The WAITS is integration between meta-heuristic whale optimization and the tabu search, hence the name. Similarly, Ahmed (2018) carried out a study in which the lexisearch and genetic algorithms were combined to form a hybrid algorithm (LSGA) that can be used in solving the QAP effectively. A hybrid method in which the Ant Colony Algorithm was combined with Tabu Search algorithm, was proposed by Lv (2012). The experimental data for this proposed hybrid algorithm indicated that the smallest average error value was obtained using the proposed hybrid algorithm. In research carried out by Da Silva et al. (2012), another hybrid algorithm was proposed. The proposed algorithm was an integration of Tabu search meta-heuristics and greedy randomized adaptive search procedure (GRASP). Their results showed that the proposed algorithm produced low-cost solutions for 50 instances. Similarly, another hybrid algorithm, which is a combination of Simulated Annealing and Tabu Search was introduced by Kaviani et al. (2014) as a solution to the QAP. In the proposed algorithm, memory structures were used through Tabu search as a means of explaining the user-provided set of rules. In contrast to other studies, in a research carried out by (Said et al., 2014) the Genetic algorithm, Simulated Annealing and Tabu Search were compared in terms of execution time. The study results revealed that the performance of the Tabu search was better than that of other metaheuristic algorithms in terms of execution time for solving practical QAP instances and the algorithm demonstrated faster execution time. Another integration was performed by Harris et al. (2015), and in their study, they integrated the Tabu Search with Memetic algorithm. Through the restarts, the solution space is explored, and the problem of convergence is avoided by the algorithm. Furthermore, the search for local optima is intensified using Tabu Search. Findings of their study revealed that the proposed algorithm was less time consuming and outperformed other methods in terms of solving real-life instances and random instances with high quality. In order to solve the QAP, Lim et al. (2016) proposed another hybrid algorithm which is formed by combining the Biogeography-Based Optimization Algorithm and Tabu Search. With the use of the proposed hybrid algorithm, the best solutions were found for 36 instances out of 37 instances. This shows that the performance of the hybrid algorithm was good. 
In other studies, attempts were made by researchers to solve the problems of discrete optimization. In such studies, modifications were made to the Differential Evolution (DE). An algorithm associated with discrete differential evolution (DDE) was proposed by (Pan et al., 2008) for the purpose of computing differences in the flow-shop preparation problem. Results of their study showed that the efficiency of the proposed algorithm was lower than that of other methods, and this was perceived to be caused using probability of low mutation (0.2). However, the DDE algorithm operation is more successful and efficient when the local search is used. In a study earlier conducted by Kushida et al. (2012) the DE was modified to a discrete optimization problem and afterward used in solving the QAP. Similarly, the use of insertion and swap was employed by Tasgetiren et al. (2013) in modifying DDE with the local search-based modification. With the use of DDE alongside local search, improvements were observed in the results of two kinds of dense and sparse instances of QAPLIB.

\section{Methods}

Three phases are involved in this section. In the first phase, discrete differential evolution algorithm (DDE) is included, the second phase includes the Tabu search algorithm TS, and finally, in the third phase, the proposed hybrid, which is a combination of both TS and DDE is introduced.

\subsection{Discrete Differential Evolution Algorithm (DDE)}

One of the most recently introduced Evolutionary Algorithm is the Differential Evolution (DE) optimization method, which was first introduced by Storn and Price (1997). The Evolutionary Algorithm is regarded as a category of efficient optimization techniques used worldwide to solve a wide range of hard problems. DE is known as a global optimizer that is constantly dependent on random space and population (Lampinen, 2005). The DE has proven to be more efficient and powerful, and for this reason, it is rapidly emerging as a popular optimizer that is used in different areas like the function of continuous real value and for solving a combinatorial optimization problem with a discrete decision. In this study, the discrete differential algorithm DDE which has been modified by (Tasgetiren et al., 2013) is used. The Discrete Differential algorithm DDE is illustrated in the flowchart in Fig. 1. and the steps of it have been introduced as follows:

I. Initialization initialize population matrix $\pi=\left\{\pi_{1}, \pi_{2}, \pi_{3}, \ldots, \pi_{N P}\right\}$ randomly. Matrix size $N P \times N D$ where $N P$ is number of population and $N D$ dimension of problem space. All population individuals should be unique.

II. Evaluate fitness: find the best solution $\pi \mathrm{b}^{\mathrm{t}-1}$ from population $\pi$.

III. Mutation: obtain the mutant individual, the following equation can be used:

$$
v_{i}^{t}= \begin{cases}\operatorname{insert}\left(\pi_{b}^{t-1}\right) & \text { if }\left(r<P_{m}\right) \\ \operatorname{swap}\left(\pi_{b}^{t-1}\right) & \text { otherwise }\end{cases}
$$

where $\pi \mathrm{b}^{\mathrm{t}-1}$ is the best solution from the previous generation in the target population; $\mathrm{P}_{\mathrm{m}}$ is the perturbation probability; and swap are simply the single insertion and swap moves, $\mathrm{r}$ is a uniform random number belong to $[0,1]$.

IV. Crossover: obtain the crossover, the following equation can be used:

$$
u_{i}^{t}= \begin{cases}C R\left(v_{i}^{t}, \pi_{i}^{t-1}\right) & \text { if }\left(r<P_{c}\right) \\ v_{i}^{t} & \text { otherwise }\end{cases}
$$


where $\pi_{\mathrm{b}}{ }^{\mathrm{t}-1}$ is the best solution from the previous generation in the target population; Pc is the crossover probability; and CR is crossover operation. then the crossover operator is applied to generate the trial individual $u_{i}^{t}$ Otherwise the trial individual is chosen as $u_{i}^{t}=v_{i}^{t}$.

V. Selection: selection is based on fitness function; the following equation can be used:

$$
\pi_{i}^{t}=\left\{\begin{array}{lr}
u_{i}^{t} & \text { if }\left(f\left(\pi_{i}^{t}\right)<f\left(\pi_{i}^{t-1}\right)\right) \\
\pi_{i}^{t-1} & \text { otherwise }
\end{array}\right.
$$

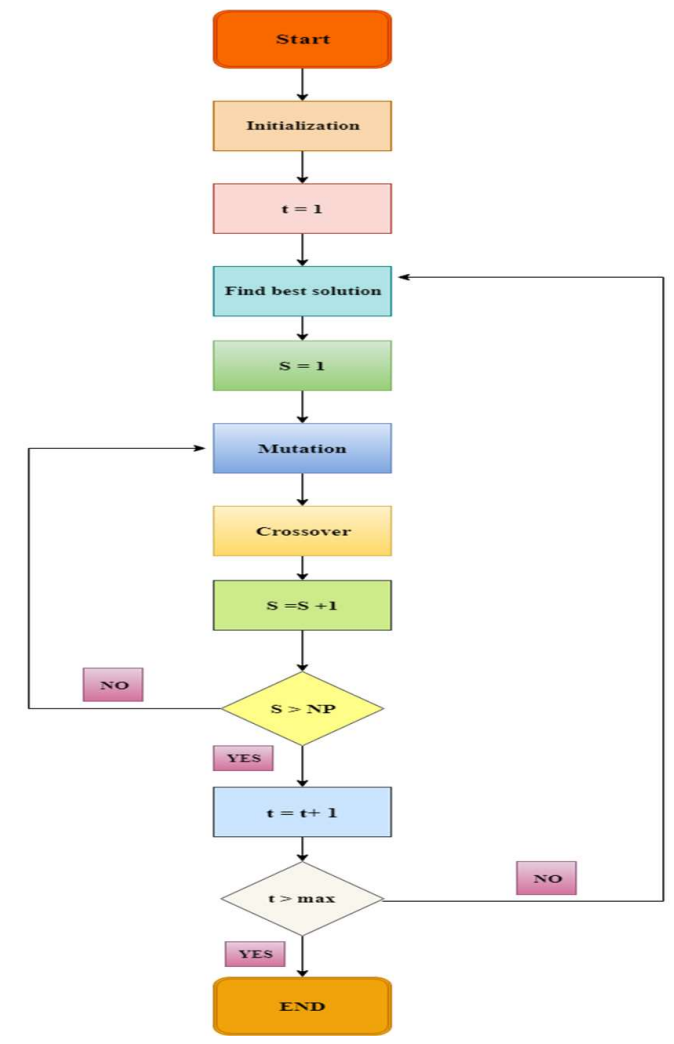

Fig. 1. Flowchart of DDE algorithm

\subsection{Tabu Search Algorithm (TS)}

In order to solve the large combinatorial optimization problem, the use of Tabu search (TS) has been employed with great success (Van Luong et al., 2010). Despite the efficiency and the meta-heuristic strength demonstrated by the TS, it is usually combined with other solutions like evolutionary computation. The central idea behind TS involves the specification of a set of moves or a neighborhood which can be used in a specific solution so as to enable the generation of a new solution (Taillard, 1991). The neighborhood solution that is considered by TS is to have the best evaluation. In an event that improving moves are absent, TS selects the neighborhood solution that has minimal effect in terms of degrading the objective function. It is possible to avoid the return to a local optimum that has just been visited by using a list of tabu. In an event that tabu moves are perceived as fascinating, the introduction of an aspiration criterion is made so that these tabu moves can be selected.

\subsection{The proposed algorithm HDDETS}

In Fig. 2 below, the HARDEST algorithm flow chart is presented. The basic steps of the HDDEST are addressed as follows: 
1- Initialization: initialize population matrix $\pi=\left\{\pi_{1}, \pi_{2}, \pi_{3}, \ldots, \pi_{N P}\right\}$ randomly. Matrix size $N P \times N D$ where $N P$ is several population and $N D$ dimension of problem space. All population individuals should be unique. Initialize set Solution Wait for each solution $\mathrm{SW}=$ array of $N P$ with zeros and maximum wait, and ht (iteration of tabu search).

2- Evaluate fitness: to the fined best solution based on the Eq. (1)

3- Mutation: use the Eq. (2)

4- Crossover: the crossover has been introduced by Eq. (3). The central idea of crossover is to leverage the best benefits from the parent algorithm during the production of the new one, which is often known as the hybrid. A wide range of crossover operators are found in the literature, and such crossover operators have been proposed by researchers with the aim of solving quadratic assignment problem. In this study, the crossover which has been used is referred to as the uniform-like crossover (ULX) which was introduced by (Tate \& Smith, 1995). The crossover was obtained as follows:

- The offspring inherits any facility which is has been allocated to the same location in both parents

- The selection of every unallocated facility is carried out randomly so as to ensure that each facility that is unassigned is chosen just once. Here, a random selection of one of the parents is made. In a situation whereby the location of the chosen facility is unoccupied, the offspring inherits it. However, if the location is occupied in the first parent, then an attempt is made to allocate the location of the facility from the second parent.

- Once a location has been allocated to a facility, it is marked. If the facility which is allocated to this location in the parent that was used in the previous rule is not allocated, the offspring inherits it.

5- apply the TS for a hybrid: TS used to an enhancement of the solution based on some characteristics as follows:

i. Intensification: In Intensification the promising area is explored more fully in the hope to find the best solutions by using neighborhood search, the size of a neighborhood is $n(n-1) / 2$ and calculated through the following:

$$
\begin{aligned}
& \Delta \operatorname{cost}(\pi, \mathrm{i}, \mathrm{j})=\left(\mathrm{a}_{\mathrm{ii}}-\mathrm{a}_{\mathrm{jj}}\right)\left(\mathrm{b}_{\pi(\mathrm{j}) \pi(\mathrm{j})}-\mathrm{b}_{\pi(\mathrm{i}) \pi(\mathrm{j})}\right)+\left(\mathrm{a}_{\mathrm{ij}}-\mathrm{a}_{\mathrm{ji}}\right)\left(\mathrm{b}_{\pi(\mathrm{j}) \pi(\mathrm{i})}-\mathrm{b}_{\pi(\mathrm{i}) \pi(\mathrm{j})}\right)+ \\
& \sum_{k=1, k \neq i, j}^{n}\left(\mathrm{a}_{\mathrm{ik}}-\mathrm{a}_{\mathrm{jk}}\right)\left(\mathrm{b}_{\pi(\mathrm{j}) \pi(\mathrm{k})}-\mathrm{b}_{\pi(\mathrm{i}) \pi(\mathrm{k})}\right)+\left(\mathrm{a}_{\mathrm{ki}}-\mathrm{a}_{\mathrm{kj}}\right)\left(\mathrm{b}_{\pi(\mathrm{k}) \pi(\mathrm{j})}-\mathrm{b}_{\pi(\mathrm{k}) \pi(\mathrm{i})}\right)
\end{aligned}
$$

where $a_{i i}, a_{j j}=0, i=1,2, \ldots, n, k=1,2,3, \ldots, n$ such that $k \neq i, k \neq j$

ii. Tabu list: The tabu list has been used to avoid the solution which visited in the past.

6- Selection: selection is based on fitness function; the following equation can be used:

$$
\pi_{i}^{t}=\left\{\begin{array}{lr}
u_{i}^{t} & \text { if }\left(f\left(\pi_{i}^{t}\right)<f\left(\pi_{i}^{t-1}\right)\right) \\
\pi_{i}^{t-1} & \text { otherwise }
\end{array}\right.
$$

\section{7- Update solution waiting:}

$$
S W^{i}=\left\{\begin{array}{cc}
0 & \pi_{i}^{t}=u_{i}^{t} \\
S W^{i}+1 & \pi_{i}^{t}=\pi_{i}^{t-1}
\end{array}\right.
$$




\subsubsection{Pseudo-code of HDDETS algorithm}

Generate population matrix $\pi=\left\{\pi_{1}, \pi_{2}, \pi_{3}, \ldots, \pi_{N P}\right\}$ randomly. Matrix size is $N P \times N D$ where $N P$ is the number of population and $N D$ is the dimension of problem space. Max_t $=$ number of maximum iterations. Set Solution Wait for each solution $S W=$ array of $N P$. Max_ht $=$ number of maximum iterations of TS.

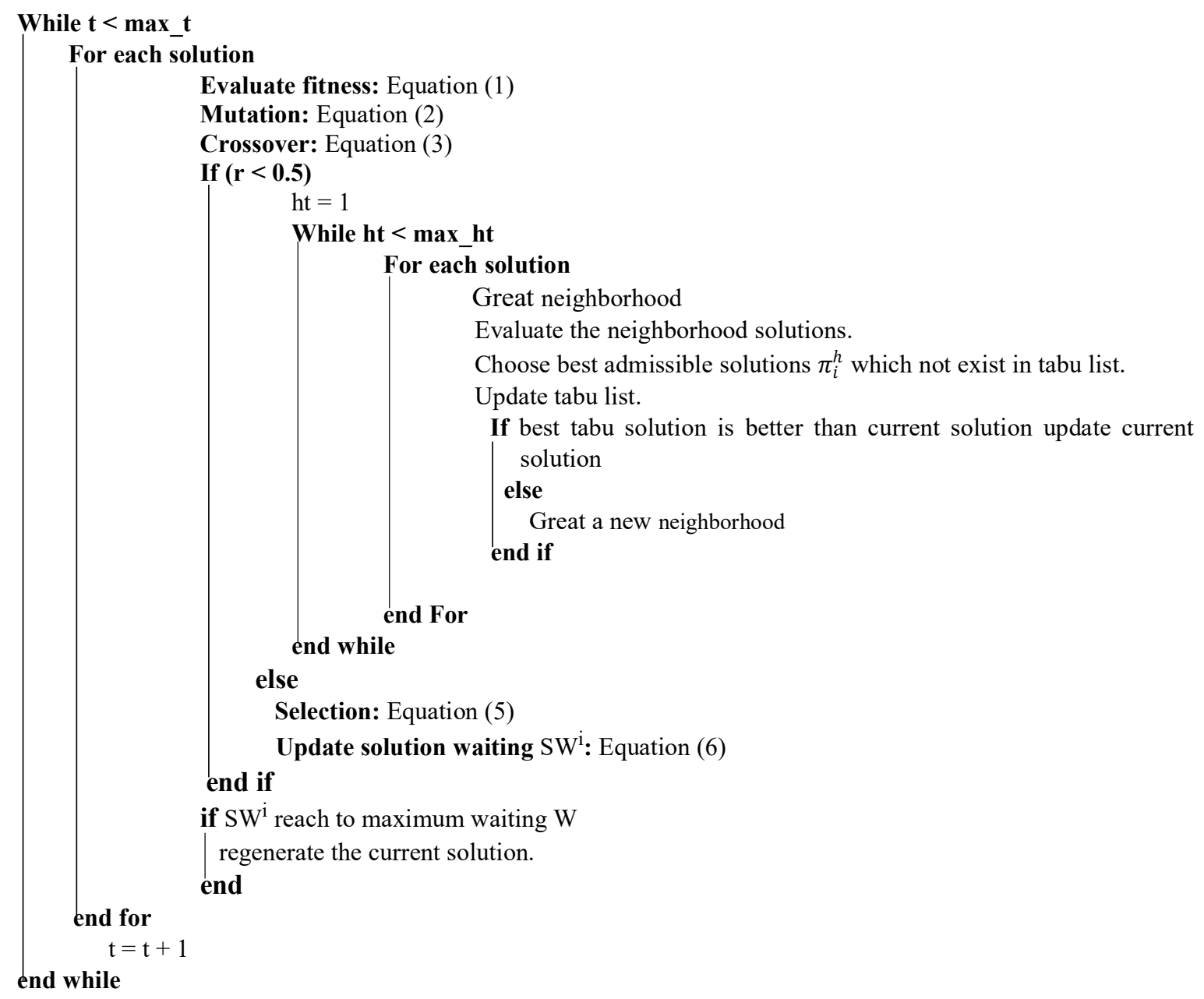




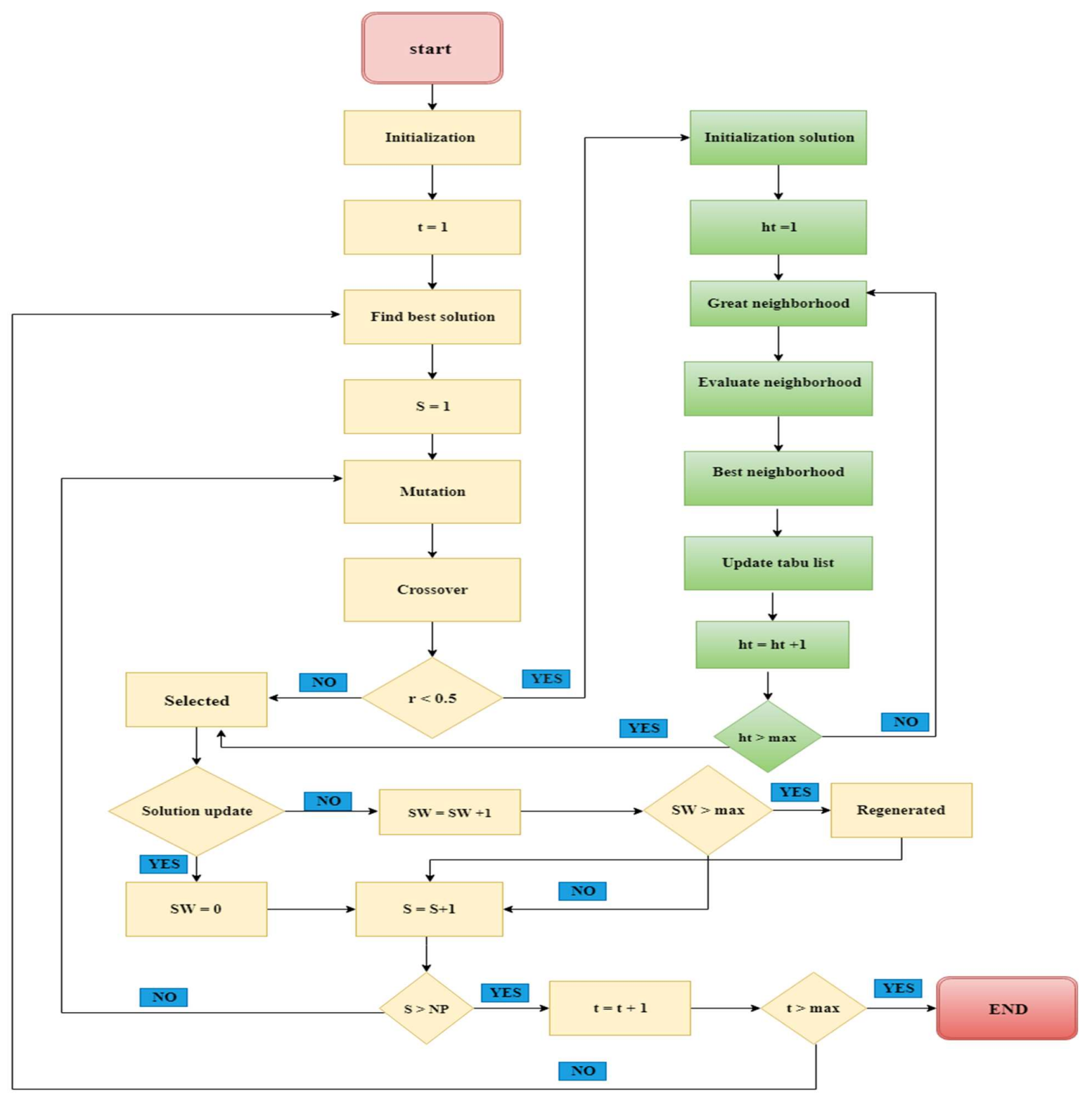

Fig. 2. Flowchart of HDDETS algorithm

\section{Computational Results}

In this section, the efficiency of the proposed algorithm is presented. In order to encode the proposed algorithm, MATLAB was employed on a PC with Intel (R) Core (TM) i7-3770 CPU @ 3.40 GHz. Also, the PC which was used operates under MS Windows 10 and has a RAM of 4GB. This section consists of two parts, and the first part highlights the parameters used for the proposed algorithm, while in the second part the results of the study are discussed. The results were obtained using the proposed algorithm. The proposed algorithm has been applied to seven categories of instances from QAPLIB as Table 1. 
Table 1

Instances of QAP from QAPLIB

\begin{tabular}{|c|c|c|c|c|c|c|}
\hline 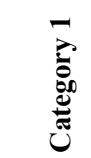 & 苛 & 苛 & 苛 & 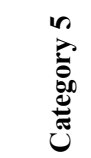 & 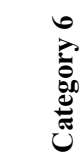 & 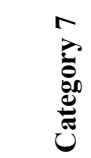 \\
\hline Tai12a & Nug12 & Chr12a & Esc16a & Lipa20a & Had12 & Sko42 \\
\hline Tai12b & Nug14 & Chr12b & Esc16b & Lipa20b & Had14 & Sko49 \\
\hline Tail5a & Nug15 & Chrl2c & Esc16c & Lipa30a & Had 16 & Sko56 \\
\hline Tail5b & Nug16a & Chr15a & Esc16d & Lipa30b & Had 18 & Sko64 \\
\hline Tail7a & Nug16b & Chr15b & Esc16e & Lipa40a & Had20 & Sko72 \\
\hline Tai20a & Nug17 & Chr15c & Esc16f & Lipa 40 b & - & Sko81 \\
\hline Tai20b & Nug18 & Chr18a & Esc16g & Lipa50a & - & Sko90 \\
\hline Tai25a & Nug20 & Chr18b & Esc16h & Lipa50b & - & Sko100a \\
\hline Tai25b & Nug21 & $\mathrm{Chr} 20 \mathrm{a}$ & Esc16i & Lipa60a & - & Sko100b \\
\hline Tai30a & Nug22 & Chr20b & Esc16j & Lipa60b & - & Sko $100 \mathrm{c}$ \\
\hline Tai30b & Nug24 & $\mathrm{Chr} 20 \mathrm{c}$ & Esc32a & Lipa70a & - & Skolo0d \\
\hline Tai35a & Nug25 & $\mathrm{Chr} 22 \mathrm{a}$ & Esc $32 b$ & Lipa70b & - & Sko100e \\
\hline Tai35b & Nug27 & $\mathrm{Chr} 22 \mathrm{~b}$ & Esc $32 c$ & Lipa80a & - & Skol00f \\
\hline Tai40a & Nug28 & Chr25a & Esc32d & Lipa 80 b & - & - \\
\hline Tai40b & Nug30 & - & Esc $32 e$ & Lipa90a & - & - \\
\hline Tai50a & - & - & Esc $32 \mathrm{~g}$ & Lipa90b & - & - \\
\hline Tais0b & - & - & Esc $32 \mathrm{~h}$ & - & - & - \\
\hline Tai60a & - & - & Esc64a & - & - & - \\
\hline Tai64c & - & - & Esc128a & - & - & - \\
\hline Tai80a & - & - & - & - & - & - \\
\hline Tai80b & - & - & - & - & - & - \\
\hline Tai100a & - & - & - & - & - & - \\
\hline Tai100b & - & - & - & - & - & - \\
\hline Tai150b & - & & & & & \\
\hline Tai256c & - & & & & & \\
\hline
\end{tabular}

\subsection{Parameter setting}

In order to determine the most appropriate parameter settings, extensive experiments, as well as many runs of the algorithm, were performed. The set values of the parameters for the three algorithms were presented in Table 2. The quality of the solutions obtained by using the proposed algorithm can be influenced by the set algorithm parameters. To identify the most suitable set of parameter values that produce desirable outcomes, numerous tests were performed.

Table 2

Parameter setting

\begin{tabular}{lc}
\hline \multicolumn{1}{c}{ Parameter } & Value \\
\hline NP Number of Population & 200 \\
Maximum Iterations & 100 \\
$\mathrm{P}_{\mathrm{m}}$ Perturbation Probability of Mutation & 0.7 \\
$\mathrm{P}_{\mathrm{c}}$ Perturbation Probability of Crossover & 0.8 \\
$\mathrm{P}_{\mathrm{h}}$ Probability of Hybrid & 0.5 \\
Maximum waiting for solutions updates & 10 \\
Tabu list length & 10 \\
Maximum iterations of TS & 25 \\
Number of runs & 10 \\
\hline
\end{tabular}

\subsection{Results and Discussions}

This section shows the computational results of the efficiency of the proposed algorithm. The suggested algorithm HDDETS has been run on 10 different instances made up of problems that are referred to as follows: Tai, Nug, Chr, Esc, Lipa, Had, and Sko. Table3 shows the instances which have been used in this study. The QAP size falls within the range of 12 to 256. Many statistical analyses have been carried out for every instance which include the best solution, worst solution, average solution, best gap, worst gap, average gap, standard deviation, and time. The experiment show the effect of integrating the tabu search algorithm TS with the discrete differential evolution algorithm DDE. The performance of the 
algorithm which is proposed in this study HDDETS was evaluated by comparing it with other algorithms. Specific criteria which include quality of solution and measured running times were used in comparing the algorithms. The use of quality of solution criterion for comparison of algorithms is more appropriate in heuristic and estimation methods, especially (in optimization). On the other hand, the running time comparison criterion is the most appropriate for exact algorithms. However, in a case where the produced solutions are similar in terms of quality, comparison of running times of approximation algorithms and heuristics will be suitable. This work focused on solution quality. The accuracy of an algorithm is calculated using a percentage deviation or gap. In this study, the solution quality criterion was used in calculating the accuracy, which is calculated through the question below:

$$
\mathrm{Gap}=\left(\mathrm{C}_{\text {Best }}-\mathrm{C}^{*}\right) / \mathrm{C}^{*} \times 100 \text {, }
$$

where $\mathrm{C}_{\mathrm{Best}}$ is the best objective value found over 10 runs, while $\mathrm{C}^{*}$ is the best-known value taken from QAPLIB. The results of the proposed algorithm (HDDETS) are presented in Table 3. The results are discussed using three scenarios as follows:

\section{Scenario 1:}

The proposed algorithm was applied to the cases shown in Table 1. All the numerical results were excellent and have been presented in Table 3. It was found that the proposed algorithm achieved an accuracy of $100 \%$ in 83 test instances out of 105 test instances. These excellent results can be attributed to the use of an algorithm feature that can continuously improve all the solutions in each iteration until the best solution is reached. The strength of this algorithm is due to the integration of the diversification property of the algorithm DDE with the intensification feature of TS algorithm, as well as the use of tabulist which prevents the recurrence of solutions that have been visited in the past.

Table 3

Results of the HDDETS algorithm for some instances from QAPLIB

\begin{tabular}{|c|c|c|c|c|c|c|c|c|c|c|}
\hline 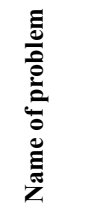 & 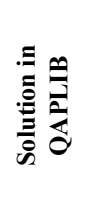 & 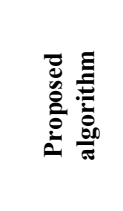 & 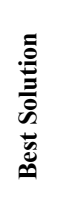 & 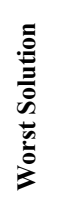 & 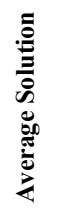 & 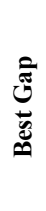 & 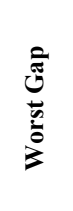 & 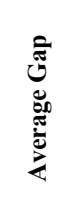 & 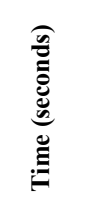 & 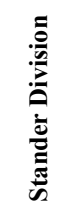 \\
\hline Nug12 & 578 & HDDETS & 578 & 578 & 578 & 0 & 0 & 0 & 0.514 & 0 \\
\hline Nug14 & 1014 & HDDETS & 1014 & 1014 & 1014 & 0 & 0 & 0 & 0.432 & 0 \\
\hline Nug15 & 1150 & HDDETS & 1150 & 1150 & 1150 & 0 & 0 & 0 & 0.378 & 0 \\
\hline Nug16a & 1610 & HDDETS & 1610 & 1610 & 1610 & 0 & 0 & 0 & 0.573 & 0 \\
\hline Nug16b & 1240 & HDDETS & 1240 & 1240 & 1240 & 0 & 0 & 0 & 0.461 & 0 \\
\hline Nug17 & 1732 & HDDETS & 1732 & 1732 & 1732 & 0 & 0 & 0 & 4.204 & 0 \\
\hline Nug18 & 1930 & HDDETS & 1930 & 1930 & 1930 & 0 & 0 & 0 & 0.526 & 0 \\
\hline Nug20 & 2570 & HDDETS & 2570 & 2570 & 2570 & 0 & 0 & 0 & 1.889 & 0 \\
\hline Nug21 & 2438 & HDDETS & 2438 & 2438 & 2438 & 0 & 0 & 0 & 2.275 & 0 \\
\hline Nug22 & 3596 & HDDETS & 3596 & 3596 & 3596 & 0 & 0 & 0 & 1.672 & 0 \\
\hline Nug24 & 3488 & HDDETS & 3488 & 3488 & 3488 & 0 & 0 & 0 & 1.99 & 0 \\
\hline Nug25 & 3744 & HDDETS & 3744 & 3744 & 3744 & 0 & 0 & 0 & 3.201 & 0 \\
\hline Nug27 & 5234 & HDDETS & 5234 & 5234 & 5234 & 0 & 0 & 0 & 1.299 & 0 \\
\hline Nug28 & 5166 & HDDETS & 5166 & 5166 & 5166 & 0 & 0 & 0 & 43.434 & 0 \\
\hline Nug30 & 6124 & HDDETS & 6124 & 6148 & 6126 & 0 & 0.391 & 0.039 & 3.273 & 0.123 \\
\hline Chr12a & 9552 & HDDETS & 9552 & 9552 & 9552 & 0 & 0 & 0 & 0.518 & 0 \\
\hline Chr12b & 9742 & HDDETS & 9742 & 9742 & 9742 & 0 & 0 & 0 & 0.281 & 0 \\
\hline Chr12c & 11156 & HDDETS & 11156 & 11156 & 11156 & 0 & 0 & 0 & 0.558 & 0 \\
\hline Chr15a & 9896 & HDDETS & 9896 & 9896 & 9896 & 0 & 0 & 0 & 1.077 & 0 \\
\hline Chr15b & 7990 & HDDETS & 7990 & 7990 & 7990 & 0 & 0 & 0 & 0.369 & 0 \\
\hline Chr15c & 9504 & HDDETS & 9504 & 9504 & 9504 & 0 & 0 & 0 & 2.026 & 0 \\
\hline Chr18a & 11098 & HDDETS & 11098 & 11098 & 11098 & 0 & 0 & 0 & 1.01 & 0 \\
\hline Chr18b & 1534 & HDDETS & 1534 & 1534 & 1534 & 0 & 0 & 0 & 0.522 & 0 \\
\hline Chr20a & 2192 & HDDETS & 2192 & 2192 & 2192 & 0 & 0 & 0 & 2.057 & 0 \\
\hline Chr20b & 2298 & HDDETS & 2298 & 2298 & 2298 & 0 & 0 & 0 & 50.772 & 0 \\
\hline Chr20c & 14142 & HDDETS & 14142 & 14142 & 14142 & 0 & 0 & 0 & 0.849 & 0 \\
\hline Chr22a & 6156 & HDDETS & 6156 & 6156 & 6156 & 0 & 0 & 0 & 51.954 & 0 \\
\hline Chr22b & 6194 & HDDETS & 6194 & 6194 & 6194 & 0 & 0 & 0 & 64.016 & 0 \\
\hline Chr25a & 3796 & HDDETS & 3796 & 3796 & 3796 & 0 & 0 & 0 & 9.588 & 0 \\
\hline
\end{tabular}


Table 3

Results of the HDDETS algorithm for some instances from QAPLIB (Continued)

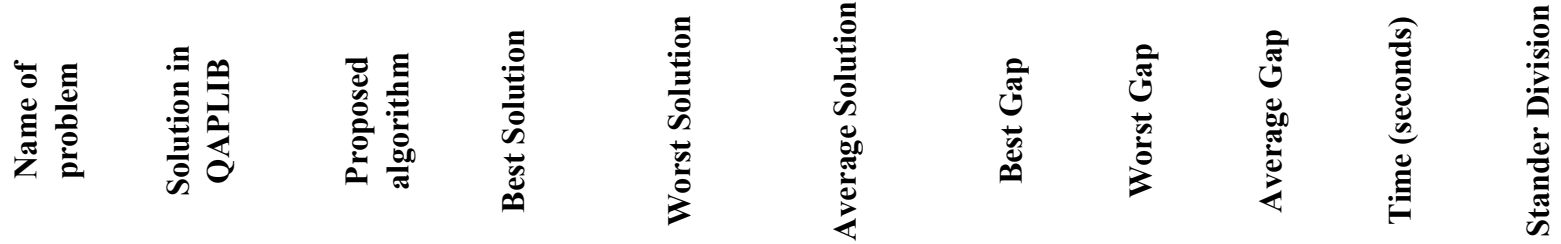

\begin{tabular}{|c|c|c|c|c|c|c|c|c|c|c|}
\hline Sko42 & 15812 & HDDETS & 15812 & 15818 & 15814 & 0 & 0.037 & 0.015 & 20.864 & 0.019 \\
\hline Sko49 & 23386 & HDDETS & 23386 & 23440 & 23403 & 0 & 0.23 & 0.072 & 27.001 & 0.063 \\
\hline Sko56 & 34458 & HDDETS & 34458 & 34580 & 34503 & 0 & 0.354 & 0.131 & 623.89 & 0.132 \\
\hline Sko64 & 48498 & HDDETS & 48498 & 48902 & 48622 & 0 & 0.833 & 0.255 & 858.975 & 0.241 \\
\hline Sko72 & 66256 & HDDETS & 66316 & 66626 & 66429 & 0.09 & 0.558 & 0.261 & 368.841 & 0.136 \\
\hline Sko81 & 90998 & HDDETS & 91060 & 91524 & 91313 & 0.068 & 0.578 & 0.346 & 1624.424 & 0.18 \\
\hline Sko90 & 115534 & HDDETS & 115756 & 116498 & 116046 & 0.192 & 0.834 & 0.443 & 1727.96 & 0.197 \\
\hline Sko100a & 152002 & HDDETS & 152316 & 154014 & 152725 & 0.206 & 1.323 & 0.475 & 2969.776 & 0.382 \\
\hline Sko100b & 153890 & HDDETS & 154168 & 155054 & 154600 & 0.18 & 0.756 & 0.461 & 1490.758 & 0.189 \\
\hline Sko100c & 147862 & HDDETS & 148148 & 149426 & 148753 & 0.193 & 1.057 & 0.602 & 2930.167 & 0.325 \\
\hline Sko100d & 149576 & HDDETS & 149762 & 150512 & 150217 & 0.124 & 0.625 & 0.428 & 1472.923 & 0.15 \\
\hline Sko100e & 149150 & HDDETS & 149514 & 151034 & 150024 & 0.244 & 1.263 & 0.585 & 6488.738 & 0.341 \\
\hline Sko100f & 149063 & HDDETS & 149714 & 150464 & 149919 & 0.454 & 0.958 & 0.592 & 1265.821 & 0.144 \\
\hline Tai12a & 224416 & HDDETS & 224416 & 224416 & 224416 & 0 & 0 & 0 & 0.508 & 0 \\
\hline Tai12b & 39464925 & HDDETS & 39464925 & 39464925 & 39464925 & 0 & 0 & 0 & 0.684 & 0 \\
\hline Tai15a & 388214 & HDDETS & 388214 & 388214 & 388214 & 0 & 0 & 0 & 0.847 & 0 \\
\hline Tai15b & 51765268 & HDDETS & 51765268 & 51765268 & 51765268 & 0 & 0 & 0 & 0.81 & 0 \\
\hline Tai17a & 491812 & HDDETS & 491812 & 491812 & 491812 & 0 & 0 & 0 & 5 & 0 \\
\hline Tai20a & 703482 & HDDETS & 703482 & 706786 & 704026 & 0 & 0.469 & 0.077 & 5.653 & 0.167 \\
\hline Tai20b & 122455319 & HDDETS & 122455319 & 122455319 & 122455319 & 0 & 0 & 0 & 0.511 & 0 \\
\hline Tai25a & 1167256 & HDDETS & 1167256 & 1174422 & 1170285 & 0 & 0.613 & 0.259 & 7.848 & 0.209 \\
\hline Tai25b & 344355646 & HDDETS & 344355646 & 344355646 & 344355646 & 0 & 0 & 0 & 13.46 & 0 \\
\hline Tai30a & 1818146 & HDDETS & 1818146 & 1818146 & 1818146 & 0 & 0 & 0 & 57.4 & 0 \\
\hline Tai30b & 637117113 & HDDETS & 637117113 & 637117113 & 637117113 & 0 & 0 & 0 & 29.794 & 0 \\
\hline Tai35a & 2422002 & HDDETS & 2422002 & 2431810 & 2423613 & 0 & 0.404 & 0.066 & 29.589 & 0.131 \\
\hline Tai35b & 283315445 & HDDETS & 283315445 & 283315445 & 283315445 & 0 & 0 & 0 & 57.4 & 0 \\
\hline Tai40a & 3139370 & HDDETS & 3141431 & 3151727 & 3148060 & 0.065 & 0.393 & 0.276 & 138.357 & 0.087 \\
\hline Tai40b & 637250948 & HDDETS & 637250948 & 650062131 & 638532066 & 0 & 2.01 & 0.201 & 416.445 & 0.635 \\
\hline Tai50a & 4938796 & HDDETS & 4989160 & 5010958 & 5002852 & 1.019 & 1.461 & 1.297 & 768.214 & 0.162 \\
\hline Tai50b & 458821517 & HDDETS & 458821517 & 460726849 & 459656699 & 0 & 0.415 & 0.182 & 48.479 & 0.194 \\
\hline Tai60a & 7205962 & HDDETS & 7281638 & 7338518 & 7309055 & 1.05 & 1.839 & 1.43 & 921.089 & 0.263 \\
\hline Tai60b & $608,215,054$ & HDDETS & 7205962 & 608501817 & 640242782 & 0.047 & 5.265 & 1.526 & 42.188 & 1.616 \\
\hline Tai64c & 1855928 & HDDETS & 1855928 & 1855928 & 1855928 & 0 & 0 & 0 & 8.308 & 0 \\
\hline Tai80a & 13499184 & HDDETS & 13642148 & 13749540 & 13690956 & 1.059 & 1.854 & 1.42 & 1195.736 & 0.215 \\
\hline Tai80b & 818415043 & HDDETS & 818415043 & 831997039 & 824550128 & 0 & 1.659 & 0.749 & 1399.883 & 0.561 \\
\hline Tai100a & 21125314 & HDDETS & 21269898 & 21395720 & 21342495 & 1.069 & 1.667 & 1.414 & 2740.755 & 0.202 \\
\hline Tai100b & 1185996137 & HDDETS & 1187179912 & 1212182931 & 1191632007 & 0.099 & 2.208 & 0.475 & 1553.481 & 0.624 \\
\hline Tai150b & 498896643 & HDDETS & 501892435 & 508173332 & 505261057 & 0.6 & 1.859 & 1.275 & 9402.76 & 0.442 \\
\hline Tai256c & 44759294 & HDDETS & 44786418 & 44838798 & 44813276 & 0.06 & 0.177 & 0.12 & 41014.57 & 0.041 \\
\hline Esc16a & 68 & HDDETS & 68 & 68 & 68 & 0 & 0 & 0 & 0.533 & 0 \\
\hline Esc16b & 292 & HDDETS & 292 & 292 & 292 & 0 & 0 & 0 & 0.634 & 0 \\
\hline Esc16c & 160 & HDDETS & 160 & 160 & 160 & 0 & 0 & 0 & 0.577 & 0 \\
\hline Esc16d & 16 & HDDETS & 16 & 16 & 16 & 0 & 0 & 0 & 0.532 & 0 \\
\hline Esc16e & 28 & HDDETS & 28 & 28 & 28 & 0 & 0 & 0 & 0.55 & 0 \\
\hline Esc16f & 0 & HDDETS & 0 & 0 & 0 & 0 & 0 & 0 & 0.426 & 0 \\
\hline Esc16g & 26 & HDDETS & 26 & 26 & 26 & 0 & 0 & 0 & 0.472 & 0 \\
\hline Esc16h & 996 & HDDETS & 996 & 996 & 996 & 0 & 0 & 0 & 0.473 & 0 \\
\hline Esc16i & 14 & HDDETS & 14 & 14 & 14 & 0 & 0 & 0 & 0.629 & 0 \\
\hline Esc16j & 8 & HDDETS & 8 & 8 & 8 & 0 & 0 & 0 & 0.737 & 0 \\
\hline Esc32a & 130 & HDDETS & 130 & 130 & 130 & 0 & 0 & 0 & 7.953 & 0 \\
\hline Esc32b & 168 & HDDETS & 168 & 168 & 168 & 0 & 0 & 0 & 1.924 & 0 \\
\hline Esc32c & 642 & HDDETS & 642 & 642 & 642 & 0 & 0 & 0 & 2.276 & 0 \\
\hline Esc32d & 200 & HDDETS & 200 & 200 & 200 & 0 & 0 & 0 & 2.184 & 0 \\
\hline Esc32e & 2 & HDDETS & 2 & 2 & 2 & 0 & 0 & 0 & 1.835 & 0 \\
\hline Esc32g & 6 & HDDETS & 6 & 6 & 6 & 0 & 0 & 0 & 1.907 & 0 \\
\hline Esc $32 \mathrm{~h}$ & 438 & HDDETS & 438 & 438 & 438 & 0 & 0 & 0 & 1.896 & 0 \\
\hline Esc64a & 116 & HDDETS & 116 & 116 & 116 & 0 & 0 & 0 & 9.927 & 0 \\
\hline Esc128a & 64 & HDDETS & 64 & 64 & 64 & 0 & 0 & 0 & 55.614 & 0 \\
\hline
\end{tabular}


Table 3

Results of the HDDETS algorithm for some instances from QAPLIB (Continued)

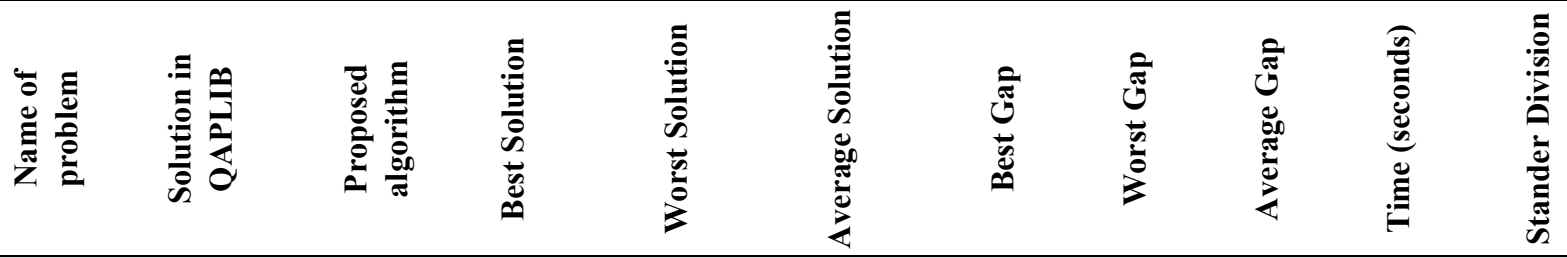

\begin{tabular}{|c|c|c|c|c|c|c|c|c|c|c|}
\hline Lipa20a & 3683 & HDDETS & 3683 & 3683 & 3683 & 0 & 0 & 0 & 1.351 & 0 \\
\hline Lipa 20b & 27076 & HDDETS & 27076 & 27076 & 27076 & 0 & 0 & 0 & 1.011 & 0 \\
\hline Lipa30a & 131178 & HDDETS & 131178 & 131178 & 131178 & 0 & 0 & 0 & 9.965 & 0 \\
\hline Lipa30b & 151426 & HDDETS & 151426 & 151426 & 151426 & 0 & 0 & 0 & 5.141 & 0 \\
\hline Lipa40a & 31538 & HDDETS & 31538 & 31844 & 31684 & 0 & 0.97 & 0.461 & 16.246 & 0.487 \\
\hline Lipa40b & 476581 & HDDETS & 476581 & 476581 & 476581 & 0 & 0 & 0 & 6.946 & 0 \\
\hline Lipa50a & 62093 & HDDETS & 62093 & 62629 & 62451 & 0 & 0.863 & 0.576 & 42.387 & 0.398 \\
\hline Lipa50b & 1210244 & HDDETS & 1210244 & 1210244 & 1210244 & 0 & 0 & 0 & 32.891 & 0 \\
\hline Lipa60a & 107218 & HDDETS & 107897 & 108019 & 107959 & 0.633 & 0.747 & 0.69 & 463.998 & 0.034 \\
\hline Lipa60b & 2520135 & HDDETS & 2520135 & 2969956 & 2742733 & 0 & 17.849 & 8.832 & 433.066 & 9.311 \\
\hline Lipa70a & 169755 & HDDETS & 170787 & 170858 & 170824 & 0.607 & 0.649 & 0.629 & 1056.769 & 0.014 \\
\hline Lipa70b & 4603200 & HDDETS & 4603200 & 5475784 & 5285704 & 0 & 18.956 & 14.8267 & 470.74 & 7.818 \\
\hline Lipa80a & 253195 & HDDETS & 254506 & 254695 & 254590 & 0.517 & 0.592 & 0.551 & 719.781 & 0.023 \\
\hline Lipa80b & 7763962 & HDDETS & 7763962 & 9293826 & 9131465 & 0 & 19.7047 & 17.613 & 176.991 & 6.189 \\
\hline Lipa90a & 360630 & HDDETS & 362307 & 362601 & 362480 & 0.465 & 0.546 & 0.513 & 2000.489 & 0.026 \\
\hline Lipa90b & 12490441 & HDDETS & 12490441 & 15002587 & 14479768 & 0 & 20.112 & 15.926 & 1851.828 & 8.395 \\
\hline Had12 & 1652 & HDDETS & 1652 & 1652 & 1652 & 0 & 0 & 0 & 0.784 & 0 \\
\hline Had14 & 2724 & HDDETS & 2724 & 2724 & 2724 & 0 & 0 & 0 & 0.583 & 0 \\
\hline Had16 & 3720 & HDDETS & 3720 & 3720 & 3720 & 0 & 0 & 0 & 0.437 & 0 \\
\hline Had18 & 5358 & HDDETS & 5358 & 5358 & 5358 & 0 & 0 & 0 & 0.674 & 0 \\
\hline Had20 & 6922 & HDDETS & 6922 & 6922 & 6922 & 0 & 0 & 0 & 0.837 & 0 \\
\hline
\end{tabular}

\section{Scenario 2:}

All solutions for all cases mentioned in the database of QAP are divided into two types:

- Optimal Solution (OPT)

- Best Known Solution (BKS)

In this study, the number of instances that have the Optimal Solution is 77 instances and the number of instances that have the Best-Known Solution is 28 instances. An Optimal Solution can be obtained by the proposed algorithm in 73 instances out of 77 instances and it can produce Best Known Solution in 10 instances out of 28 instances. The first comparison was done in this study to evaluate the effectiveness of the proposed algorithm HDDETS. The proposed algorithm was compared with TS and DDE. In Table 4 , the results of the comparison are presented, and it can be observed from the results that the HDDETS outperformed DDE and TS in all instances. Afterward, another comparison has been carried out between the proposed algorithm and another algorithm in the literature. Prior to the proposal of a hybrid algorithm in this study, a new approach called whale algorithm integrated with Tabu search for quadratic assignment problem (WAITS) had been introduced by (Abdel-Basset et al., 2018a). A comparison was done between the WAITS and the algorithm proposed in this study. Based on the outcome of the comparison, the performance of WAITS is better than that of other algorithms in terms of solving QAP. More so, it can produce an optimal solution for many instances of QAP.

Table 4 shows the comparison between our proposed HDDETS and WAITS. The main contribution of this study is providing an improved solution for QAP, especially that which has not produced an optimal solution. For instance, in the case of (Tai50a, Tai80b, Tai100a, and Tai150b) the best gap of this instance was reached at $(1.57 \%, 1.20 \%, 2.04 \%$, and $1.76 \%$ respectively) compared with the solution in a dataset of QAP. By applying our proposed algorithm to solve the instance (Tai50a, Tai80b, Tai100a, and Tai150b) this gap was reduced to $(0 \%, 0 \%, 1.146 \%$, and $0.6 \%$ respectively). Table 4 shows our contribution in terms of providing improved solutions for QAP. In the instances of (Sko49, Sko56, Sko64, Sko72, Sko100b, and Sko100e), many researchers have developed several optimization methods 
to improve the solutions of these instances so that they can reach the best or the same values within the database for QAP. So far, the best gap has been found for these cases by WAITS as follows: $(0.13 \%$, $0.08 \%, 0.07 \%, 0.27 \%, 0.74 \%$, and $0.76 \%$, respectively). Another contribution of the algorithm HDDETS is enhancing the solutions of these instances; the results produced by HDDETS were found to be better than those of WAITS. More so, HDDETS reached the best gap of $(0 \%, 0 \%, 0 \%, 0.09 \%, 0.18$ $\%$, and $0.124 \%$, respectively). Below are the figures (Figs. 3-9) that show the gaps obtained from the algorithms in Table 4. In Table 5 below, a summary of the comparison results between HDDETS and WAITS is presented.

Table 4

Comparative results between DDE, TS, HDDETS, and WAITS algorithms for QAP

\begin{tabular}{|c|c|c|c|c|c|c|}
\hline \multirow[t]{2}{*}{ No. } & \multirow[t]{2}{*}{ Problem } & \multirow[t]{2}{*}{$\begin{array}{l}\text { Best-Known } \\
\text { Solution }\end{array}$} & DDE & TS & HDDETS & \multirow[t]{2}{*}{ WAITS } \\
\hline & & & Best gap & Best gap & Best gap & \\
\hline 1 & Chr12a & 9552 & 0 & 3.810 & 0 & 0 \\
\hline 2 & Chr12b & 9742 & 0 & 0 & 0 & 0 \\
\hline 3 & Chr12c & 11156 & 2.312 & 2.312 & 0 & 0 \\
\hline 4 & Chr15a & 9896 & 0 & 9.256 & 0 & 0 \\
\hline 5 & Chr15b & 7990 & 14.167 & 23.329 & 0 & 0 \\
\hline 6 & Chr18a & 11098 & 27.967 & 26.872 & 0 & 0 \\
\hline 7 & Chr18b & 1534 & 30.365 & 11.155 & 0 & 0 \\
\hline 8 & Chr20a & 2192 & 1.825 & 7.561 & 0 & 0 \\
\hline 9 & Chr20b & 2298 & 13.594 & 20.255 & 0 & 1.56 \\
\hline 10 & Chr20c & 14142 & 15.665 & 13.838 & 0 & 0 \\
\hline 11 & Chr22a & 6156 & 40.347 & 35.384 & 0 & 0.16 \\
\hline 12 & Chr22b & 6194 & 9.096 & 8.219 & 0 & 0 \\
\hline 13 & Chr25a & 3796 & 8.653 & 7.426 & 0 & 0 \\
\hline 14 & Esc16a & 68 & 0 & 0 & 0 & 0 \\
\hline 15 & Esc16b & 292 & 0 & 0 & 0 & 0 \\
\hline 16 & Esc 16c & 160 & 0 & 0 & 0 & 0 \\
\hline 17 & Esc16d & 16 & 0 & 0 & 0 & 0 \\
\hline 18 & Esc 16e & 28 & 0 & 0 & 0 & 0 \\
\hline 19 & Esc16f & 0 & 0 & 0 & 0 & 0 \\
\hline 20 & Esc16g & 26 & 0 & 0 & 0 & 0 \\
\hline 21 & Esc16h & 996 & 0 & 0 & 0 & 0 \\
\hline 22 & Esc16i & 14 & 0 & 0 & 0 & 0 \\
\hline 23 & Esc16j & 8 & 0 & 15.3846 & 0 & 0 \\
\hline 24 & Esc $32 \mathrm{a}$ & 130 & 20 & 14.2857 & 0 & 0 \\
\hline 25 & Esc $32 b$ & 168 & 19.047 & 0 & 0 & 0 \\
\hline 26 & Esc $32 c$ & 642 & 0 & 0 & 0 & 0 \\
\hline 27 & Esc $32 d$ & 200 & 0 & 0 & 0 & 0 \\
\hline 28 & Esc32e & 2 & 0 & 0 & 0 & 0 \\
\hline 29 & Esc $32 \mathrm{~g}$ & 6 & 0 & 0.91324 & 0 & 0 \\
\hline 30 & Esc $32 \mathrm{~h}$ & 438 & 0.913 & 0 & 0 & 0 \\
\hline 31 & Esc64a & 116 & 0 & 0 & 0 & 0 \\
\hline 32 & Esc128a & 64 & 34.375 & 0 & 0 & 0 \\
\hline 33 & Lipa20a & 3683 & 1.710 & 2.1721 & 0 & 0 \\
\hline 34 & Lipa20b & 27076 & 14.791 & 0 & 0 & 0 \\
\hline 35 & Lipa30a & 131178 & 1.844 & 1.7529 & 0 & 0 \\
\hline 36 & Lipa30b & 151426 & 15.766 & 15.7998 & 0 & 0 \\
\hline 37 & Lipa40a & 31538 & 1.417 & 1.4554 & 0 & 0 \\
\hline 38 & Lipa40b & 476581 & 19.009 & 18.2678 & 0 & 0 \\
\hline 39 & Lipa50a & 62093 & 1.3673 & 1.3705 & 0 & 0 \\
\hline 40 & Lipa50b & 1210244 & 19.278 & 19.2295 & 0 & 0 \\
\hline 41 & Lipa60a & 107218 & 1.221 & 1.2759 & 0.633 & 0 \\
\hline 42 & Lipa60b & 2520135 & 21.013 & 21.2654 & 0 & 0 \\
\hline 43 & Lipa70a & 169755 & 1.122 & 1.1611 & 0.607 & 0 \\
\hline 44 & Lipa 70b & 4603200 & 22.022 & 22.1949 & 0 & 0 \\
\hline 45 & Lipa80a & 253195 & 1.029 & 1.0861 & 0.517 & 0.55 \\
\hline 46 & Lipa80b & 7763962 & 23.047 & 23.4897 & 0 & 0 \\
\hline 47 & Lipa90a & 360630 & 0.963 & 1.0559 & 0.465 & 0.50 \\
\hline 48 & Lipa90b & 12490441 & 23.243 & 24.0423 & 0 & 0 \\
\hline
\end{tabular}


Table 4

Comparative results between DDE, TS, HDDETS, and WAITS algorithms for QAP (Continued)

\begin{tabular}{|c|c|c|c|c|c|c|}
\hline \multirow[t]{2}{*}{ No. } & \multirow[t]{2}{*}{ Problem } & \multirow[t]{2}{*}{$\begin{array}{l}\text { Best-Known } \\
\text { Solution }\end{array}$} & DDE & TS & HDDETS & \multirow[t]{2}{*}{ WAITS } \\
\hline & & & Best gap & Best gap & Best gap & \\
\hline 49 & Nug12 & 578 & 1.73 & 2.422 & 0 & 0 \\
\hline $\mathbf{5 0}$ & Nug14 & 1014 & 2.366 & 0 & 0 & 0 \\
\hline 51 & Nug16a & 1150 & 2.782 & 0.173 & 0 & 0 \\
\hline 52 & Nug16b & 1610 & 2.608 & 0.993 & 0 & 0 \\
\hline 53 & Nug17 & 1240 & 3.225 & 1.774 & 0 & 0 \\
\hline 54 & Nug18 & 1930 & 0.923 & 1.732 & 0 & 0 \\
\hline 55 & Nug20 & 2570 & 0.310 & 0.932 & 0 & 0 \\
\hline 56 & Nug21 & 2438 & 1.400 & 1.4 & 0 & 0 \\
\hline 57 & Nug22 & 3596 & 1.230 & 2.297 & 0 & 0 \\
\hline 58 & Nug24 & 3488 & 1.724 & 0.166 & 0 & 0 \\
\hline 59 & Nug25 & 3744 & 2.216 & 2.867 & 0 & 0 \\
\hline 60 & Nug27 & 5234 & 1.442 & 1.121 & 0 & 0 \\
\hline 61 & Nug28 & 5166 & 1.528 & 3.248 & 0 & 0 \\
\hline 62 & Nug30 & 6124 & 3.832 & 4.065 & 0 & 0.52 \\
\hline 63 & Sko42 & 15812.0 & 2.567 & 4.3638 & 0 & 0 \\
\hline 64 & Sko49 & 23386 & 1.599 & 4.8833 & 0 & 0.13 \\
\hline 65 & Sko56 & 34458 & 2.704 & 5.2876 & 0 & 0.08 \\
\hline 66 & Sko64 & 48498 & 3.365 & 5.2909 & 0 & 0.07 \\
\hline 67 & Sko72 & 66256 & 3.595 & 6.7164 & 0.09 & 0.27 \\
\hline 68 & Sko81 & 90998 & 3.356 & 6.2815 & 0.068 & 0.19 \\
\hline $\begin{array}{l}00 \\
69\end{array}$ & Sko90 & 115534 & 3.661 & 7.1183 & 0.192 & 0.56 \\
\hline 70 & Sko100a & 152002 & 3.326 & 7.2039 & 0.206 & 0.76 \\
\hline 71 & Sko100b & 153890 & 3.184 & 6.6723 & 0.18 & 0.74 \\
\hline 72 & Sko100c & 147862 & 3.907 & 7.3799 & 0.193 & 0.99 \\
\hline 73 & Sko100d & 149576 & 3.866 & 7.3394 & 0.124 & 0.98 \\
\hline 74 & Sko100e & 149150 & 3.886 & 7.3067 & 0.244 & 0.76 \\
\hline 75 & Sko100f & 149036 & 3.616 & 6.899 & 0.454 & 0.95 \\
\hline 76 & Had12 & 1652 & 0.121 & 0 & 0 & 0 \\
\hline 77 & Had14 & 2724 & 0.22 & 0 & 0 & 0 \\
\hline 78 & Had16 & 3720 & 0.86 & 0 & 0 & 0 \\
\hline 79 & Had18 & 5358 & 0.298 & 0.074 & 0 & 0 \\
\hline 80 & $\mathrm{Had} 20$ & 6922 & 1.126 & 0.086 & 0 & 0 \\
\hline 81 & Tai12a & 224416 & 0 & 3.842 & 0 & 0 \\
\hline 82 & Tai12b & 39464925 & 2.8496 & 4.263 & 0 & 0 \\
\hline 83 & Tai15a & 388214 & 2.043 & 0.16898 & 0 & 0 \\
\hline 84 & Tai15b & 51765268 & 0.339 & 2.4024 & 0 & 0 \\
\hline 85 & Tai20a & 491812 & 2.983 & 0.90165 & 0 & 0 \\
\hline 86 & Tai20b & 703482 & 4.592 & 4.3505 & 0 & 0 \\
\hline 87 & Tai25a & 122455319 & 1.743 & 1.6315 & 0 & 0 \\
\hline 88 & Tai25b & 1167256 & 4.216 & 4.0909 & 0 & 0 \\
\hline 89 & Tai30a & 344355646 & 2.039 & 6.5651 & 0 & 0.48 \\
\hline 90 & Tai30b & 1818146 & 4.548 & 5.5332 & 0 & 0 \\
\hline 91 & Tai35a & 637117113 & 3.502 & 4.0868 & 0 & 0.06 \\
\hline 92 & Tai35b & 2422002 & 4.777 & 6.3761 & 0 & 0 \\
\hline 93 & Tai40a & 3139370 & 2.157 & 0.092568 & 0 & 0.52 \\
\hline 94 & Tai40b & 637250948 & 4.748 & 6.9324 & 0.065 & 0.005 \\
\hline 95 & Tai50a & 637250948 & 0.0769 & 11.4704 & 0 & 1.57 \\
\hline 96 & Tai50b & 4938796 & 5.246 & 12.7767 & 1.019 & 0.05 \\
\hline 97 & Tai60a & 458821517 & 3.388 & 13.2447 & 0 & 1.93 \\
\hline 98 & Tai60b & 7205962 & 4.609 & 1.974 & 0.047 & 0.74 \\
\hline 99 & Tai64c & 1855928 & 0.4175 & 2.4024 & 0 & 0 \\
\hline 100 & Tai80a & 13499184 & 5.665 & 0.90165 & 1.059 & 1.90 \\
\hline 101 & Tai80b & 818415043 & 7.486 & 4.3505 & 0 & 1.20 \\
\hline 102 & Tai100a & 21125314 & 5.743 & 1.6315 & 1.146 & 2.04 \\
\hline 103 & Tai100b & 1185996137 & 7.116 & 4.0909 & 0.099 & 0.50 \\
\hline 104 & Tai150b & 498896643 & 8.6079 & 6.5651 & 0.6 & 1.76 \\
\hline 105 & Tai256c & 44759294 & 1.5643 & 2.1909 & 0.06 & 0.26 \\
\hline
\end{tabular}


Below the figures which show the gaps obtained from the performance of the algorithms in Table 4 .

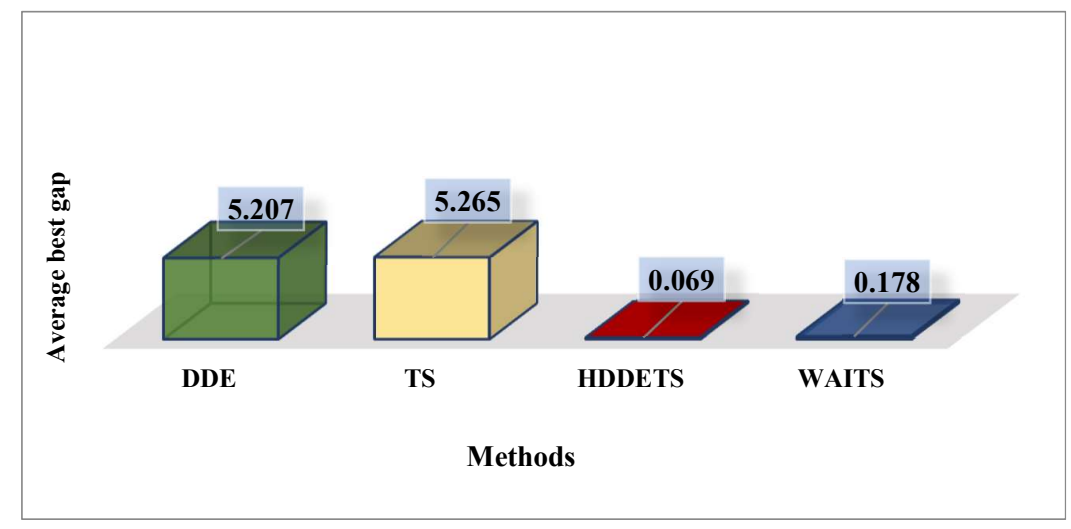

Fig. 2. comparison among DDE, TS, HDDETS, and WAITS

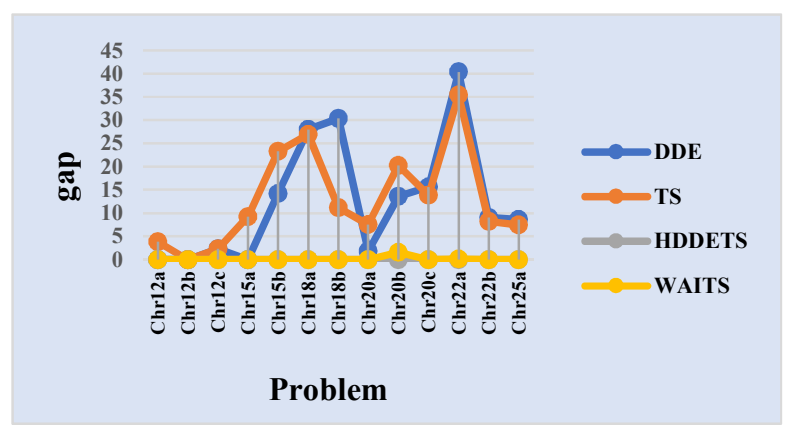

Fig. 3. Comparison on instance $\mathrm{Chr}$

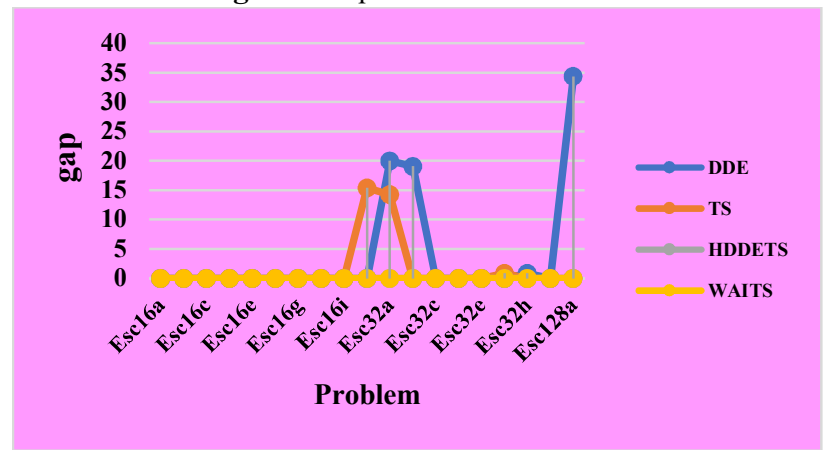

Fig. 5. Comparison on instance Esc

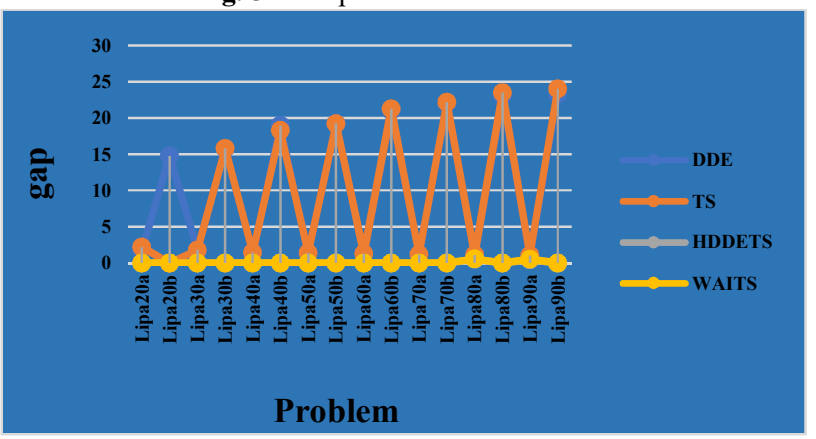

Fig. 7. Comparison on instance Lipa

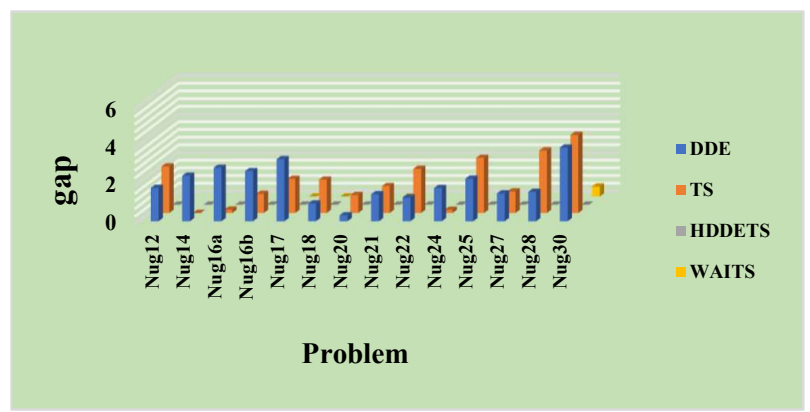

Fig. 4. Comparison on instance Nug

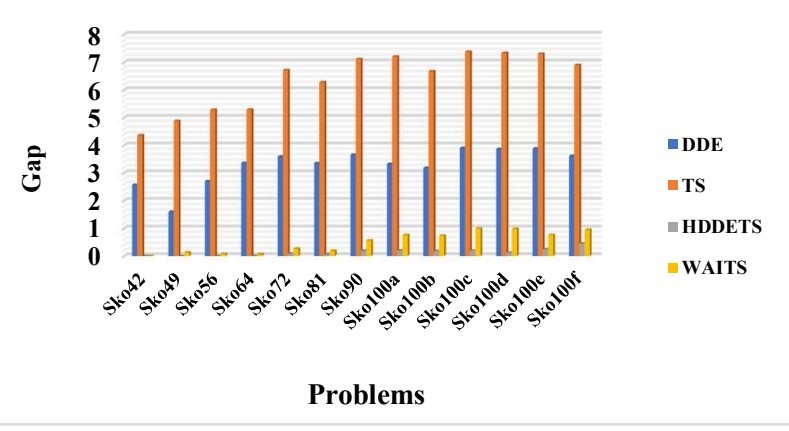

Fig. 6. Comparison on instance Sko

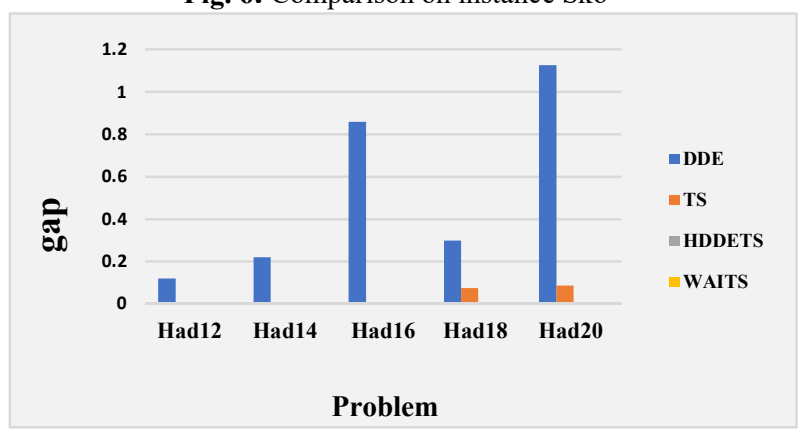

Fig. 8. Comparison on instance Lipa 


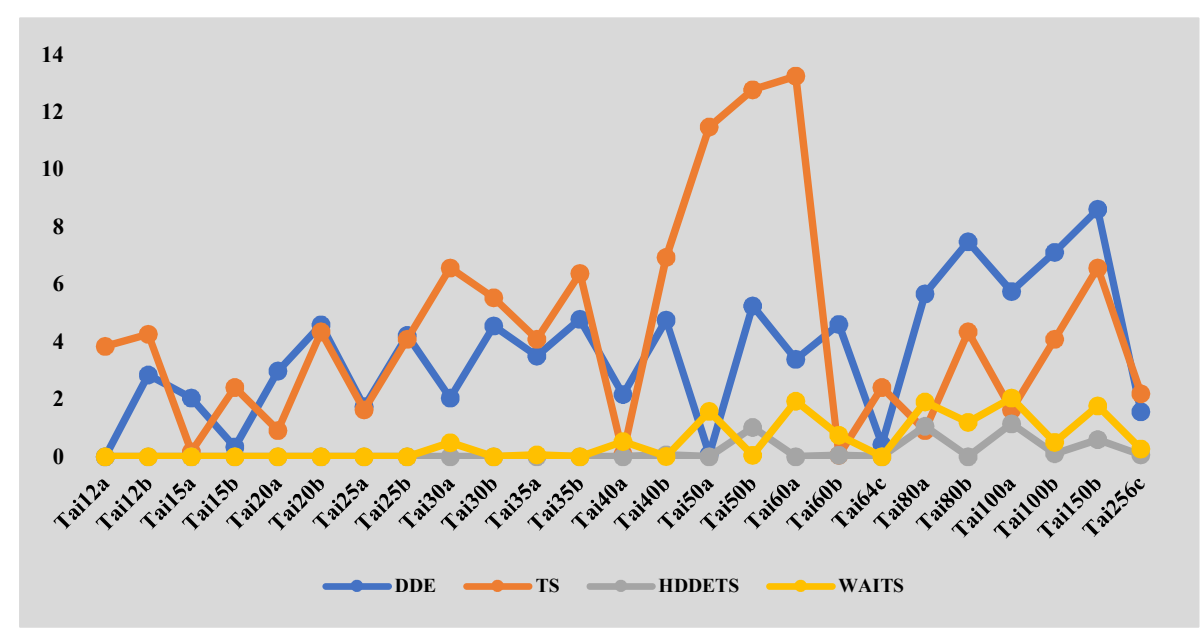

Fig. 9. Comparison on instance Tai

Table 5 presents a summary of the comparison results between HDDETS and WAITS.

Table 5

Summary of the comparison results between HDDETS and WAITS

\begin{tabular}{|c|c|c|c|c|c|c|c|c|}
\hline \multirow[t]{2}{*}{ Category } & \multirow{2}{*}{$\begin{array}{l}\text { Name of } \\
\text { Problem }\end{array}$} & \multirow{2}{*}{$\begin{array}{c}\text { Number of } \\
\text { Instances }\end{array}$} & \multicolumn{2}{|c|}{ Type of Solution } & \multicolumn{2}{|c|}{ HDDETS } & \multicolumn{2}{|c|}{ WAITS } \\
\hline & & & OPT & BKS & OPT & BKS & OPT & BKS \\
\hline 1 & Tai & 25 & 10 & 15 & 10 & 7 & 8 & 3 \\
\hline 2 & Nug & 14 & 14 & - & 14 & - & 13 & - \\
\hline 3 & $\mathrm{Chr}$ & 13 & 13 & - & 13 & - & 11 & - \\
\hline 4 & Esc & 19 & 19 & - & 19 & - & 19 & - \\
\hline 5 & Lipa & 16 & 16 & - & 12 & - & 14 & - \\
\hline 6 & $\mathrm{Had}$ & 5 & 5 & - & 5 & - & 5 & - \\
\hline 7 & Sko & 13 & - & 13 & - & 3 & - & 1 \\
\hline Sum & & 105 & 77 & 28 & 73 & 10 & 70 & 4 \\
\hline
\end{tabular}

\section{Scenario 3:}

In the next step, the effect and validation of the proposed algorithm HDDETS are presented. This is achieved by comparing the proposed algorithm with other algorithms. The most robust and latest algorithms were used for the comparison. Table 6 shows the results of the comparison between HDDETS and four other algorithms. Comparisons between HDDETS and the following algorithms were done:

- Discrete Bat Algorithm (DBA) (Riffi et al., 2017)

- Development of modified discrete particle swarm (DPSO) (Pradeepmon, 2018)

- Biogeography-Based Optimization Algorithm Hybridized with Tabu Search (BBOTS) (Lim et al., 2016)

- A hybrid algorithm combining lexisearch and genetic algorithms (LSGA) (Ahmed, 2018)

For the compared cases in Table 6, the first comparison which was between HDDETS and DBA, it was found that the DBA can reach the optimal solution for 35 out of 54 instances and reach to Best Known Solution for 5 out of 21 instances. While the HDDETS has been solved 54 optimal solutions out of 54 instances, this implies that the gap of the best value found was $0 \%$. On another hand, it was observed that the HDDETS can reach the Best-Known Solution for 12 out of 21 instances. The results obtained by the DBA algorithm are as follows: the optimal solution was achieved for $(8$ instances from case Bur out of 8 instances, 5 instances from the case Chr out of 5 instances, 10 instances from the case Esc out of 10 instances, 3 instances from the case Nug out of 15 instances, and 9 instances from the case Tai out of 10). For the best-known solution in case Tai, the DBA can reach 4 instances out of 14 instances, the best 
value for the best average gap report is $0.872 \%$. HDDETS can found 8 best-known solutions out of 14 instances with the best value is $0.333 \%$ of the average gap. Next test for the best-known solution has been applied on a case Sko, the results show DBA found 1 best-known solution out for 7 instances with the best average gap value is $0.208 \%$. Whereas HDDETS has been reached to 4 best-known solutions out for 7 instances and the best average gap is $0.05 \%$.

The next comparison was between HDDETS and DPSO; DPSO has been tested on 23 instances of QAP which produced optimal solutions. The results have shown that one optimal solution was found, and the results recorded the best value for an average gap for the rest of the instances at $0.618 \%$. When the HDDETS was applied to these instances, it was found that HDDETS has the capability of improving all the 23 instances, while reducing the gap to $0 \%$ for all these instances. Similarly, the proposed algorithm has been compared with BBOTS, and this algorithm was applied in 5 cases (Bur, Chr, Esc, Nug, and Tai) of QAP. The results of these comparisons are as follows: in the case of Bur, the best value of the average gap was found to be $0.003 \%$. On the other hand, results obtained from the proposed algorithm HDDETS achieved an average gap of $0 \%$. For cases $\mathrm{Chr}$, the difference between the results was obvious, where the performance of HDDETS was better than BBOTS; the average gap obtained by HDDETS was 0.185 $\%$, while the best average gap was $0 \%$. The results of the comparison were equal to an average gap for both BBOTS and HDDETS algorithms in case Esc. For the case of Nug, the results for BBOTS in terms of the best value for the average gap was $0.019 \%$, while it was found that the HDDETS can lower the average gap to $0 \%$. On the other hand, for instances (tai12a, tai15a, tai17a, tai20a, tai30a, and tai80a) the BBOTS algorithm was used to solve these cases, and the average gap of $0.892 \%$ was achieved, while the use of HDDETS to solve these instances enhanced the reduction of the best average rate to $0 \%$.

Table 6

Comparison among DBA, DPSO, BBOTS, and HDDETS

\begin{tabular}{|c|c|c|c|c|c|c|c|c|c|c|c|}
\hline \multirow[t]{2}{*}{ No. } & \multirow[t]{2}{*}{ Problem } & \multicolumn{2}{|c|}{ Type of Solve } & \multicolumn{2}{|c|}{ DBA } & \multicolumn{2}{|c|}{ DPSO } & \multicolumn{2}{|c|}{ BBOTS } & \multicolumn{2}{|c|}{ HDDETS } \\
\hline & & OPT & BKS & Best Solve & Gap & $\begin{array}{l}\text { Best } \\
\text { Solve }\end{array}$ & Gap & $\begin{array}{l}\text { Best } \\
\text { Solve }\end{array}$ & Gap & Best Solve & Gap \\
\hline 1 & bur26a & $5,426,670$ & - & $5,426,670$ & 0 & 5434783 & 0.150 & 5426670 & 0.028 & $5,426,670$ & 0 \\
\hline 2 & bur26b & $3,817,852$ & - & $3,817,852$ & 0 & 3824420 & 0.172 & 3817852 & 0 & $3,817,852$ & 0 \\
\hline 3 & bur26c & $5,426,795$ & - & $5,426,795$ & 0 & 5428396 & 0.030 & 5426795 & 0 & $5,426,795$ & 0 \\
\hline 4 & bur26d & $3,821,225$ & - & $3,821,225$ & 0 & 3821419 & 0.005 & 3821225 & 0 & $3,821,225$ & 0 \\
\hline 5 & bur26e & $5,386,879$ & - & $5,386,879$ & 0 & 5387320 & 0.008 & 5386879 & 0 & $5,386,879$ & 0 \\
\hline 6 & bur26f & $3,782,044$ & - & $3,782,044$ & 0 & 3783123 & 0.029 & 3782044 & 0 & $3,782,044$ & 0 \\
\hline 7 & bur26g & $10,117,172$ & - & $10,117,172$ & 0 & 10118542 & 0.014 & 10117172 & 0 & $10,117,172$ & 0 \\
\hline 8 & bur26h & $7,098,658$ & - & $7,098,658$ & 0 & 7099677 & 0.014 & 7098658 & 0 & $7,098,658$ & 0 \\
\hline 9 & $\operatorname{chr} 12 \mathrm{a}$ & 9552 & - & 9552 & 0 & - & - & 9552 & 0 & 9552 & 0 \\
\hline 10 & chr12b & 9742 & - & 7990 & - & - & - & 9742 & 0 & 9742 & 0 \\
\hline 11 & $\operatorname{chr} 12 \mathrm{c}$ & 11156 & - & - & - & - & - & 11156 & 0 & 11156 & 0 \\
\hline 12 & $\operatorname{chr} 15 a$ & 9896 & - & - & - & - & - & 9896 & 0 & 9896 & 0 \\
\hline 13 & $\operatorname{chr} 15 b$ & 7990 & - & - & 0 & - & - & 7990 & 0.298 & 7990 & 0 \\
\hline 14 & $\operatorname{chr} 15 \mathrm{c}$ & 9504 & - & - & - & - & - & 9504 & 0 & 9504 & 0 \\
\hline 15 & $\operatorname{chr} 18 \mathrm{a}$ & 11098 & - & 11,098 & 0 & - & - & 11098 & 0.079 & 11098 & 0 \\
\hline 16 & chr18b & 1534 & - & - & - & - & - & 1534 & 0 & 1534 & 0 \\
\hline 17 & chr20a & 2192 & - & - & - & - & - & 2192 & 0.876 & 2192 & 0 \\
\hline 18 & chr20c & 14142 & - & 14,142 & 0 & - & - & 14142 & 0.604 & 14142 & 0 \\
\hline 19 & $\operatorname{chr} 25 a$ & 3796 & - & 3796 & 0 & - & - & - & - & 3796 & 0 \\
\hline 20 & esc16a & 68 & - & 68 & 0 & - & - & 68 & 0 & 68 & 0 \\
\hline 21 & esc16b & 292 & - & 292 & 0 & - & - & 292 & 0 & 292 & 0 \\
\hline 22 & esc16c & 160 & - & 160 & 0 & - & - & 160 & 0 & 160 & 0 \\
\hline 23 & esc16d & 16 & - & 16 & 0 & - & - & - & - & 16 & 0 \\
\hline 24 & esc16e & 28 & - & 28 & 0 & - & - & - & - & 28 & 0 \\
\hline 25 & esc16f & 0 & - & 0 & 0 & - & - & - & - & 0 & 0 \\
\hline 26 & esc32a & 130 & - & 130 & 0 & - & - & - & - & 130 & 0 \\
\hline 27 & esc32e & 2 & - & 2 & 0 & - & - & - & - & 2 & 0 \\
\hline 28 & esc $32 g$ & 6 & - & 6 & 0 & - & - & - & - & 6 & 0 \\
\hline 29 & esc64a & 116 & - & 116 & 0 & - & - & - & - & 116 & 0 \\
\hline
\end{tabular}


Table 6

Comparison among DBA, DPSO, BBOTS, and HDDETS (Continued)

\begin{tabular}{|c|c|c|c|c|c|c|c|c|c|c|c|}
\hline \multirow[t]{2}{*}{ No. } & \multirow[t]{2}{*}{ Problem } & \multicolumn{2}{|c|}{ Type of Solve } & \multicolumn{2}{|l|}{ DBA } & \multicolumn{2}{|c|}{ DPSO } & \multicolumn{2}{|c|}{ BBOTS } & \multicolumn{2}{|c|}{ HDDETS } \\
\hline & & OPT & BKS & Best Solve & Gap & $\begin{array}{c}\text { Best } \\
\text { Solve }\end{array}$ & Gap & $\begin{array}{c}\text { Best } \\
\text { Solve }\end{array}$ & Gap & Best Solve & Gap \\
\hline 30 & nug12 & 578 & - & - & - & 582 & 0.692 & 578 & 0 & 578 & 0 \\
\hline 31 & nug14 & 1014 & - & - & - & 1016 & 0.197 & 1014 & 0 & 1014 & 0 \\
\hline 32 & nug15 & 1150 & - & - & - & 1164 & 1.217 & 1150 & 0 & 1150 & 0 \\
\hline 33 & nug16a & 1610 & - & - & - & 1630 & 1.242 & 1610 & 0 & 1610 & 0 \\
\hline 34 & nug16b & 1240 & - & - & - & 1240 & 0.000 & 1240 & 0 & 1240 & 0 \\
\hline 35 & nug17 & 1732 & - & - & - & 1750 & 1.039 & 1732 & 0.012 & 1732 & 0 \\
\hline 36 & nug18 & 1930 & - & - & - & 1936 & 0.311 & 1930 & 0 & 1930 & 0 \\
\hline 37 & nug20 & 2570 & - & 2570 & 0 & 2570 & 0 & 2570 & 0 & 2570 & 0 \\
\hline 38 & nug21 & 2438 & - & 2438 & 0 & 2444 & 0.246 & 2438 & 0 & 2438 & 0 \\
\hline 39 & nug22 & 3596 & - & - & - & 3602 & 0.167 & 3596 & 0 & 3596 & 0 \\
\hline 40 & nug24 & 3488 & - & - & - & 3578 & 2.580 & 3488 & 0 & 3488 & 0 \\
\hline 41 & nug25 & 3744 & - & - & - & 3766 & 0.588 & 3744 & 0 & 3744 & 0 \\
\hline 42 & nug27 & 5234 & - & - & - & 5294 & 1.146 & 5234 & 0 & 5234 & 0 \\
\hline 43 & nug28 & 5166 & - & - & - & 5228 & 1.200 & 5166 & 0.209 & 5166 & 0 \\
\hline 44 & nug30 & 6124 & - & 6124 & 0 & 6206 & 1.339 & 6124 & 0.065 & 6124 & 0 \\
\hline 45 & tai12a & 224,416 & - & 224,416 & 0 & - & - & 224416 & 0 & 224416 & 0 \\
\hline 46 & tai12b & $39,464,925$ & - & $39,464,925$ & 0 & - & - & - & - & 39464925 & 0 \\
\hline 47 & tai15a & 388,214 & - & 388,214 & 0 & - & - & 388214 & 0 & 388214 & 0 \\
\hline 48 & tai15b & $51,765,268$ & - & $51,765,268$ & 0 & - & - & - & - & 51765268 & 0 \\
\hline 49 & tai17a & 491,812 & - & 491,812 & 0 & - & - & 491812 & 0.093 & 491812 & 0 \\
\hline 50 & tai20a & 703,482 & - & 703,482 & 0 & - & - & 705622 & 0.677 & 703482 & 0 \\
\hline 51 & tai20b & $122,455,319$ & - & $122,455,319$ & 0 & - & - & - & - & 122455319 & 0 \\
\hline 52 & tai25a & $1,167,256$ & - & $1,172,754$ & 0.47 & - & - & - & - & 1167256 & 0 \\
\hline 53 & tai25b & $344,355,646$ & - & $344,355,646$ & 0 & - & - & - & - & 344355646 & 0 \\
\hline 54 & tai30a & - & $1,818,146$ & $1,831,272$ & 0.72 & - & - & 1843224 & 1.795 & 1818146 & 0 \\
\hline 55 & tai30b & $637,117,113$ & - & $637,117,113$ & 0 & - & - & - & - & 637117113 & 0 \\
\hline 56 & tai35a & - & $2,422,002$ & $2,438,440$ & 0.67 & - & - & - & - & 2422002 & 0 \\
\hline 57 & tai35b & - & $283,315,445$ & $283,315,445$ & 0 & - & - & - & - & 283315445 & 0 \\
\hline 58 & tai40a & - & $3,139,370$ & $3,139,370$ & 1.3 & - & - & - & - & 3150391 & 0 \\
\hline 59 & tai40b & - & $637,250,948$ & $637,250,948$ & 0 & - & - & - & - & 637250948 & 0.065 \\
\hline 60 & tai50a & - & $4,938,796$ & $5,042,654$ & 2.10 & - & - & - & - & 4965748 & 0 \\
\hline 61 & tai50b & - & $458,821,517$ & $458,830,119$ & 0 & - & - & - & - & 458821517 & 1.019 \\
\hline 62 & tai60a & - & $7,205,962$ & $7,387,482$ & 2.5 & - & - & - & - & 7266970 & 0 \\
\hline 63 & tai60b & - & $608,215,054$ & $608,414,385$ & 0.03 & - & - & - & - & 1855928 & 1.05 \\
\hline 64 & tai64c & - & $1,855,928$ & $1,855,928$ & 0 & - & - & - & - & 13616880 & 0 \\
\hline 65 & tai80a & - & $13,499,184$ & $13,810,130$ & 2.30 & - & - & 13841214 & 2.788 & 818415043 & 1.059 \\
\hline 66 & tai80b & - & $818,415,043$ & $819,367,807$ & 0.11 & - & - & - & - & 818415043 & 0 \\
\hline 67 & tai100a & - & $21,052,466$ & $21,541,326$ & 2.3 & - & - & - & - & 21285950 & 1.146 \\
\hline 68 & tai100b & - & 1185996137 & 1188168753 & 0.18 & - & - & - & - & 1187179912 & 0.099 \\
\hline 69 & sko42 & - & 15,812 & 15,812 & 0 & - & - & - & - & 15812 & 0 \\
\hline 70 & sko49 & - & 23,386 & 23,421 & 0.14 & - & - & - & - & 23386 & 0 \\
\hline 71 & sko56 & - & 34,458 & 34,524 & 0.19 & - & - & - & - & 34458 & 0 \\
\hline 72 & sko64 & - & 48,498 & 48,656 & 0.32 & - & - & - & - & 48498 & 0 \\
\hline 73 & sko72 & - & 66,256 & 66,422 & 0.25 & - & - & - & - & 66256 & 0.09 \\
\hline 74 & sko81 & - & 90,998 & 91,252 & 0.27 & - & - & - & - & 91008 & 0.068 \\
\hline 75 & sko90 & - & 115,534 & 115,874 & 0.29 & - & - & - & - & 115578 & 0.192 \\
\hline
\end{tabular}

Finally, the performance of the proposed algorithm HDDETS was compared with another algorithm contained in the literature review of this study. This algorithm is a hybrid algorithm which is a combination of lexisearch and genetic algorithms (LSGA) proposed by (Ahmed, 2018). The results of this comparison have been presented in table 7. It was found that in the instances (Tai20a, Tai30a, Tai40a, Tai50a, Tai60a, Tai80a, Tai100a, Tai20b, Tai30b, Tai40b, Tai50b, Tai60b, Tai80b, Tai100b, Tai150b), the LSGA algorithm was able to solve this case with the best value of average gap of 0.665 $\%$, while the proposed algorithm HDDETS reduced this value to $0.004 \%$. On the other hand, the LSGA algorithm solved the instances (sko42, sko49, sko81, sko90, sko100a, sko100d), and the algorithm was able to find the best average gap which was $0.191 \%$, while the HDDETS reinforced the solutions of these instances and it obtained an average gap of $0.093 \%$ for these instances. Below Fig. 11 and Fig. 12 show the best gaps obtained from the performance of the algorithms in Table 7. 
Table 7

Comparison among LSGA and HDDETS

\begin{tabular}{|c|c|c|c|c|c|c|c|}
\hline \multirow[t]{2}{*}{ Instance } & \multirow[t]{2}{*}{ BKS } & \multirow{2}{*}{$\begin{array}{c}\text { LSGA } \\
\text { Gap \% } \\
\end{array}$} & \multirow{2}{*}{$\begin{array}{c}\text { HDDETS } \\
\text { Gap \% } \\
\end{array}$} & \multirow[t]{2}{*}{ Instance } & \multirow[t]{2}{*}{ BKS } & \multirow{2}{*}{$\begin{array}{c}\text { LSGA } \\
\text { Gap \% }\end{array}$} & \multirow{2}{*}{$\begin{array}{c}\text { HDDETS } \\
\text { Gap \% }\end{array}$} \\
\hline & & & & & & & \\
\hline Tai20a & 703,482 & 0.48 & 0 & sko42 & 15,812 & 0 & 0 \\
\hline Tai30a & $1,818,146$ & 1.06 & 0 & sko49 & 23,386 & 0.14 & 0 \\
\hline Tai40a & $3,139,370$ & 1.62 & 0 & sko81 & 90,998 & 0.1 & 0.068 \\
\hline Tai50a & $4,938,796$ & 1.49 & 0 & sko90 & 115,534 & 0.33 & 0.192 \\
\hline Tai60a & $7,205,962$ & 1.53 & 0 & sko100a & 152,002 & 0.26 & 0.206 \\
\hline Tai80a & $13,499,184$ & 1.53 & 0 & - & - & - & - \\
\hline Tai100a & $21,052,466$ & 1.53 & 0 & - & - & - & - \\
\hline Tai20b & $122,455,319$ & 0 & 0 & - & - & - & - \\
\hline Tai30b & $637,117,113$ & 0 & 0 & - & - & - & - \\
\hline Tai40b & $637,250,948$ & 0 & 0 & - & - & - & - \\
\hline Tai50b & $458,821,517$ & 0 & 0 & - & - & - & - \\
\hline Tai60b & $608,215,054$ & 0 & 0 & - & - & - & - \\
\hline Tai80b & $818,415,043$ & 0.01 & 0 & - & - & - & - \\
\hline Tai100b & $1,185,996,137$ & 0.01 & 0.065 & - & - & - & - \\
\hline Tai150b & $498,896,643$ & 0.72 & 0 & - & - & - & - \\
\hline AVERAGE gap & & 0.665 & 0.004 & & & 0.191 & 0.093 \\
\hline
\end{tabular}

Below Figures have been shown the gaps obtained from the performance of the algorithms in Table 7.

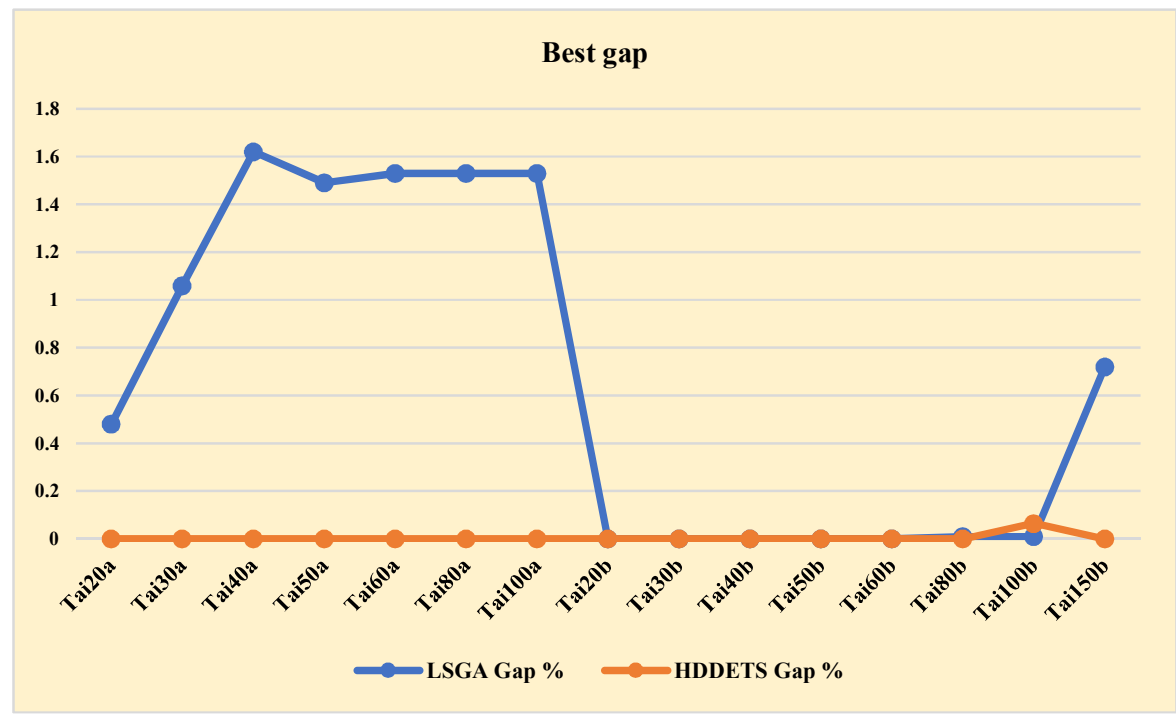

Fig. 10. Comparative study 1 between LSGA and HDDETS

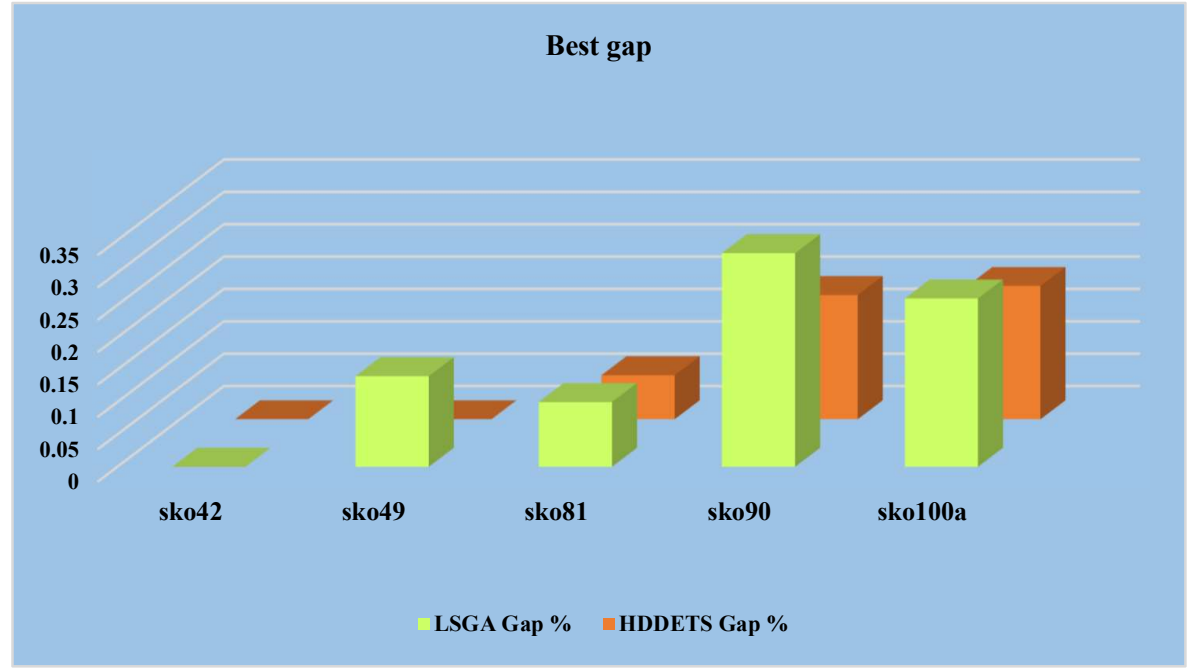

Fig. 11. Comparative study 2 between LSGA and HDDETS 


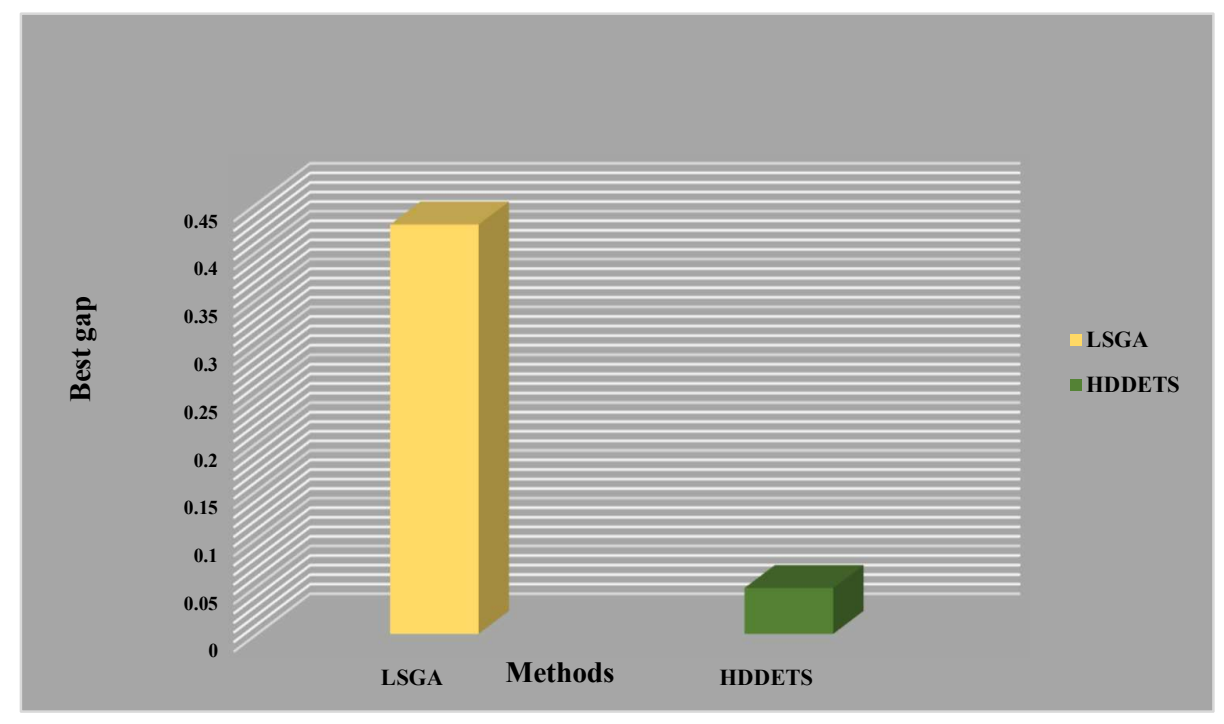

Fig. 12. Comparison on Average best for QAP

\section{Conclusion}

In this paper, a Discrete Differential Evolution algorithm hybrid with Tabu Search HDDETS has been proposed with the aim of enhancing the solution of QAP. The limitation of the standard Discrete Differential Evolution algorithm is the low level of accuracy of solutions obtained for QAP problems, and this limitation has been alleviated by the proposed approach. The comparative results have shown that HDDETS algorithm outperforms the classic DDE and TS. The HDDETS algorithm has enhanced the solutions of QAP. Seven different case studies including 105 instances have been tested and used in analyzing the performance of the proposed HDDETS. The effect of the HDDETS algorithm on improving solutions was clear and has been discussed in the results and discussions section of this paper. The results showed the contribution of HDDETS to improving solutions of QAP. The HDDETS produced 73 optimal solutions out of 77 and has reached up to 10 best-known solutions out of 28 . These are the best values obtained by the HDDETS compared to other recently proposed algorithms in the literature review in this paper. It is recommended that future research focus on the application of HDDETS algorithm in a real-world application such as Campus Layout or Hospital Layout. Another future work can focus on applying our proposed algorithm in other combinatorial optimization problems such as scheduling models or vehicle routing problem.

\section{Acknowledgment}

The authors would like to thanks to the Faculty of Information and Communication Technology, Centre for Research and Innovation Management, Universiti Teknikal Malaysia Melaka (UTeM) for providing the facilities and other support for this study.

\section{References}

Abdel-Baset, M., Wu, H., Zhou, Y., \& Abdel-Fatah, L. (2017). Elite opposition-flower pollination algorithm for quadratic assignment problem. Journal of Intelligent \& Fuzzy Systems, 33(2), 901-911.

Abdel-Basset, M., Manogaran, G., Rashad, H., \& Zaied, A. N. H. (2018a). A comprehensive review of quadratic assignment problem: variants, hybrids and applications. Journal of Ambient Intelligence and Humanized Computing, 1-24. doi: 10.1007/s12652-018-0917-x. 
Abdel-Basset, M., Manogaran, G., El-Shahat, D., \& Mirjalili, S. (2018b). Integrating the whale algorithm with tabu search for quadratic assignment problem: a new approach for locating hospital departments. Applied Soft Computing, 73, 530-546.

Abdelkafi, O., Idoumghar, L., \& Lepagnot, J. (2015). Comparison of two diversification methods to solve the quadratic assignment problem. Procedia Computer Science, 51, 2703-2707.

Ahmed, Z. H. (2018). A hybrid algorithm combining lexisearch and genetic algorithms for the quadratic assignment problem. Cogent Engineering, 5(1), 1423743.

Benlic, U., \& Hao, J. K. (2013). Breakout local search for the quadratic assignment problem. Applied Mathematics and Computation, 219(9), 4800-4815.

Cela, E., Deineko, V., \& Woeginger, G. J. (2018). New special cases of the Quadratic Assignment Problem with diagonally structured coefficient matrices. European journal of operational research, 267(3), 818-834.

Czapiński, M. (2013). An effective parallel multistart tabu search for quadratic assignment problem on CUDA platform. Journal of Parallel and Distributed Computing, 73(11), 1461-1468.

Tate, D. M., \& Smith, A. E. (1995). A genetic approach to the quadratic assignment problem. Computers \& Operations Research, 22(1), 73-83.

Doerner, K., Focke, A., \& Gutjahr, W. J. (2007). Multicriteria tour planning for mobile healthcare facilities in a developing country. European Journal of Operational Research, 179(3), 1078-1096.

Duman, E., Uysal, M., \& Alkaya, A. F. (2012). Migrating Birds Optimization: A new metaheuristic approach and its performance on quadratic assignment problem. Information Sciences, 217, 65-77.

Taillard, É. (1991). Robust taboo search for the quadratic assignment problem. Parallel computing, 17(45), 443-455.

Harris, M., Berretta, R., Inostroza-Ponta, M., \& Moscato, P. (2015, May). A memetic algorithm for the quadratic assignment problem with parallel local search. In 2015 IEEE congress on evolutionary computation (CEC) (pp. 838-845). IEEE.

Kaviani, M., Abbasi, M., Rahpeyma, B., \& Yusefi, M. (2014). A hybrid tabu search-simulated annealing method to solve quadratic assignment problem. Decision Science Letters, 3(3), 391-396.

Koopmans, T. C., \& Beckmann, M. (1957). Assignment problems and the location of economic activities. Econometrica: journal of the Econometric Society, 25(1), 53-76.

Kushida, J. I., Oba, K., Hara, A., \& Takahama, T. (2012, November). Solving quadratic assignment problems by differential evolution. In The 6th International Conference on Soft Computing and Intelligent Systems, and The 13th International Symposium on Advanced Intelligence Systems(pp. 639-644). IEEE.

Lim, W. L., Wibowo, A., Desa, M. I., \& Haron, H. (2016). A biogeography-based optimization algorithm hybridized with tabu search for the quadratic assignment problem. Computational intelligence and neuroscience, 2016, 27.

Lv, C. (2012, October). A hybrid strategy for the quadratic assignment problem. In 2012 International Conference on Information Management, Innovation Management and Industrial Engineering (Vol. 2, pp. 31-34). IEEE.

Kaviani, M., Abbasi, M., Rahpeyma, B., \& Yusefi, M. (2014). A hybrid tabu search-simulated annealing method to solve quadratic assignment problem. Decision Science Letters, 3(3), 391-396.

Pan, Q. K., Tasgetiren, M. F., \& Liang, Y. C. (2008). A discrete differential evolution algorithm for the permutation flowshop scheduling problem. Computers \& Industrial Engineering, 55(4), 795-816.

Pradeepmon, T., Sridharan, R., \& Panicker, V. (2018). Development of modified discrete particle swarm optimization algorithm for quadratic assignment problems. International Journal of Industrial Engineering Computations, 9(4), 491-508.

Pradeepmon, T. G., Panicker, V. V., \& Sridharan, R. (2016). Parameter selection of discrete particle swarm optimization algorithm for the quadratic assignment problems. Procedia Technology, 25, 9981005.

Riffi, M. E., Saji, Y., \& Barkatou, M. (2017). Incorporating a modified uniform crossover and 2exchange neighborhood mechanism in a discrete bat algorithm to solve the quadratic assignment problem. Egyptian Informatics Journal, 18(3), 221-232. 
Said, G. A. E. N. A., Mahmoud, A. M., \& El-Horbaty, E. S. M. (2014). A comparative study of metaheuristic algorithms for solving quadratic assignment problem. International Journal of Advanced Computer Science and Applications (IJACSA), 5(1), 1-6.

Shariff, S. R., Moin, N. H., \& Omar, M. (2012). Location allocation modeling for healthcare facility planning in Malaysia. Computers \& Industrial Engineering, 62(4), 1000-1010.

Şahinkoç, M., \& Bilge, Ü. (2018). Facility layout problem with QAP formulation under scenario-based uncertainty. INFOR: Information Systems and Operational Research, 56(4), 406-427.

Samanta, S., Philip, D., \& Chakraborty, S. (2018). Bi-objective dependent location quadratic assignment problem: Formulation and solution using a modified artificial bee colony algorithm. Computers \& Industrial Engineering, 121, 8-26.

Scalia, G., Micale, R., Giallanza, A., \& Marannano, G. (2019). Firefly algorithm based upon slicing structure encoding for unequal facility layout problem. International Journal of Industrial Engineering Computations, 10(3), 349-360.

Shukla, A. (2015, May). A modified bat algorithm for the quadratic assignment problem. In 2015 IEEE Congress on Evolutionary Computation (CEC) (pp. 486-490). IEEE.

Da Silva, G. C., Bahiense, L., Ochi, L. S., \& Boaventura-Netto, P. O. (2012). The dynamic space allocation problem: Applying hybrid GRASP and Tabu search metaheuristics. Computers \& Operations Research, 39(3), 671-677.

Syam, S. S., \& Côté, M. J. (2010). A location-allocation model for service providers with application to not-for-profit health care organizations. Omega, 38(3-4), 157-166.

Tasgetiren, M. F., Pan, Q. K., Suganthan, P. N., \& Dizbay, I. E. (2013, April). Metaheuristic algorithms for the quadratic assignment problem. In 2013 IEEE Symposium on Computational Intelligence in Production and Logistics Systems (CIPLS) (pp. 131-137). IEEE.

Van Luong, T., Melab, N., \& Talbi, E. G. (2010, July). Parallel hybrid evolutionary algorithms on GPU. In IEEE Congress on Evolutionary Computation (pp. 1-8). IEEE.

Xia, X., \& Zhou, Y. (2018). Performance analysis of ACO on the quadratic assignment problem. Chinese Journal of Electronics, 27(1), 26-34.

Zhang, Y., Berman, O., Marcotte, P., \& Verter, V. (2010). A bilevel model for preventive healthcare facility network design with congestion. IIE Transactions, 42(12), 865-880.

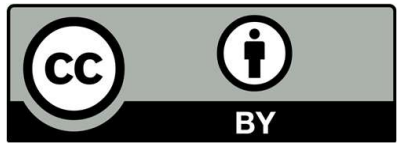

(C) 2019 by the authors; licensee Growing Science, Canada. This is an open access article distributed under the terms and conditions of the Creative Commons Attribution (CCBY) license (http://creativecommons.org/licenses/by/4.0/). 